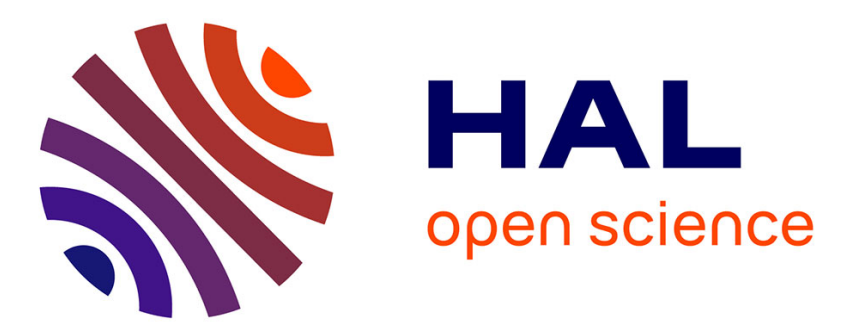

\title{
Evolution of interstellar organic compounds under asteroidal hydrothermal conditions
}

V. Vinogradoff, Samuel Bernard, C. Le Guillou, L. Remusat

\section{To cite this version:}

V. Vinogradoff, Samuel Bernard, C. Le Guillou, L. Remusat. Evolution of interstellar organic compounds under asteroidal hydrothermal conditions. Icarus, 2017, 10.1016/j.icarus.2017.12.019 . hal01700938

\section{HAL Id: hal-01700938 \\ https://hal.sorbonne-universite.fr/hal-01700938}

Submitted on 5 Feb 2018

HAL is a multi-disciplinary open access archive for the deposit and dissemination of scientific research documents, whether they are published or not. The documents may come from teaching and research institutions in France or abroad, or from public or private research centers.
L'archive ouverte pluridisciplinaire HAL, est destinée au dépôt et à la diffusion de documents scientifiques de niveau recherche, publiés ou non, émanant des établissements d'enseignement et de recherche français ou étrangers, des laboratoires publics ou privés. 


\title{
Evolution of interstellar organic compounds under asteroidal hydrothermal conditions
}

\author{
V. Vinogradoffa,*, S. Bernard ${ }^{a}$, C. Le Guillou ${ }^{b}$, L. Remusat $^{a}$ \\ a Institut de Minéralogie, Physique des Matériaux et Cosmochimie, IMPMC, Sorbonne Universités, CNRS UMR 7590, Muséum National d'Histoire Naturelle, \\ MNHN, UPMC, IRD UMR 206, Paris, France \\ ${ }^{\mathrm{b}}$ Unité Matériaux et Transformations, UMET, UMR CNRS 8207, Université Lille 1, France
}

\section{Keywords:}

Hexamethylenetetramine

Hydrothermal alteration

Carbonaceous chondrites

Interstellar organic compounds

IOM

GC-MS

FTIR

XANES

\begin{abstract}
A B S T R A C T
Carbonaceous chondrites (CC) contain a diversity of organic compounds. No definitive evidence for a genetic relationship between these complex organic molecules and the simple organic molecules detected in the interstellar medium (ISM) has yet been reported. One of the many difficulties arises from the transformations of organic compounds during accretion and hydrothermal alteration on asteroids. Here, we report results of hydrothermal alteration experiments conducted on a common constituent of interstellar ice analogs, Hexamethylenetetramine (HMT $-\mathrm{C}_{6} \mathrm{H}_{12} \mathrm{~N}_{4}$ ). We submitted HMT to asteroidal hydrothermal conditions at $150{ }^{\circ} \mathrm{C}$, for various durations (up to 31 days) and under alkaline $\mathrm{pH}$. Organic products were characterized by gas chromatography mass spectrometry, infrared spectroscopy and synchrotron-based Xray absorption near edge structure spectroscopy. Results show that, within a few days, HMT has evolved into (1) a very diverse suite of soluble compounds dominated by N-bearing aromatic compounds ( $>150$ species after 31 days), including for instance formamide, pyridine, pyrrole and their polymers (2) an aromatic and N-rich insoluble material that forms after only 7 days of experiment and then remains stable through time. The reaction pathways leading to the soluble compounds likely include HMT dissociation, formose and Maillard-type reactions, e.g. reactions of sugar derivatives with amines. The present study demonstrates that, if interstellar organic compounds such as HMT had been accreted by chondrite parent bodies, they would have undergone chemical transformations during hydrothermal alteration, potentially leading to the formation of high molecular weight insoluble organic molecules. Some of the diversity of soluble and insoluble organic compounds found in CC may thus result from asteroidal hydrothermal alteration.
\end{abstract}

\section{Introduction}

Chondrite parent bodies accreted a diversity of materials, including icy grains, minerals and organic molecules (Aléon, 2010; Boogert et al., 2015; Herbst and van Dishoeck, 2009; Remusat, 2016; Remusat et al., 2009, 2006; Scott and Krot, 2007). Carbonaceous chondrites $(\mathrm{CC})$ contain up to $4 \mathrm{wt} \%$ of organic matter (OM), dominated by an insoluble organic matter fraction (IOM - 75 to $90 \mathrm{wt} \%$ ) associated with a minor fraction of soluble organic matter (SOM - 10-25 wt\%). While the SOM is composed of a diversity of small organic molecules (such as carboxylic acids, amino acids, nucleobases, aliphatic and polycyclic aromatic hydrocarbons, sugars,...), the IOM consists in high molecular weight molecules rich in hetero-elements $(\mathrm{N}, \mathrm{S}, \mathrm{O})$ made of small aromatic units and

\footnotetext{
* Corresponding author.

E-mail address: vassilissa.vinogradoff@mnhn.fr (V. Vinogradoff).
}

short aliphatic chains (Alexander et al., 2007; Derenne and Robert, 2010; Orthous-Daunay et al., 2013; Remusat et al., 2005b, 2005a; Vinogradoff et al., 2017).

The origin of chondrite OM remains the subject of intense debates, in particular because this mixture of compounds, likely coming from different sources, may have undergone several episodes of evolution (Aléon, 2010; Alexander et al., 2017, 2007; Le Guillou et al., 2014; Remusat et al., 2010; Yabuta et al., 2007). Organic molecules may form through different processes in various astrophysical environments including molecular clouds, circumstellar envelopes and protoplanetary disks (Boogert et al., 2015; Caselli and Ceccarelli, 2012; Herbst and van Dishoeck, 2009). Pre-accretion organic synthesis may have occurred through plasma-induced condensation reactions at elevated temperatures (up to $1000 \mathrm{~K}$ ) (Kuga et al., 2015; Morgan et al., 1991; Sagan and Khare, 1979; Saito and Kimura, 2009), through gas-grain reactions (Fischer-Tropschtype process for instance) at moderated temperatures $(<600 \mathrm{~K})$ 
(Anders et al., 1973; Llorca and Casanova, 2000; Nuth et al., 2008 ) or through irradiation-driven and thermal-driven reactions within ices, usually on silicate grains, at low temperature $(<280 \mathrm{~K})$ (Allamandola et al., 1988; Bernstein et al., 1995; Ciesla and Sandford, 2012; Laurent et al., 2015; Muñoz Caro and Schutte, 2003; Theulé et al., 2013; Vinogradoff et al., 2013).

In addition to such diversity of possible sources for OM, a number of mineralogical studies of CC have pointed out that most parent bodies underwent hydrothermal alteration and metamorphism (Brearley, 2006; Keil, 2000; Mcsween, 1979). While the impact of hydrothermal processes on mineral phases has been well identified and constrained (e.g. formation of phyllosilicates, carbonates and sulfides), it remains a subject of investigations for OM (Alexander et al., 2014, 2007; Burton et al., 2012; Cody et al., 2011; Cody and Alexander, 2005; Glavin et al., 2010; Le Guillou et al., 2014; Martins and Sephton, 2009; Orthous-Daunay et al., 2013; Remusat et al., 2010; Vinogradoff et al., 2017; Yabuta et al., 2017). The present study aims at experimentally constrain the impact of hydrothermal alteration on a molecule that is typically formed in interstellar ice analogs.

Ice experiments are conducted to simulate the evolution processes of the interstellar ice-mantled dust from early molecular cloud phase to planetary disk phase (Allamandola et al., 1988; Bernstein et al., 1995; Muñoz Caro and Schutte, 2003). They are classically performed by irradiation (usually at $10 \mathrm{~K}$ ) with ultraviolet light (UV) or charged particles, and/or by warming of ice mixtures composed of water, methanol and ammonia. When warmed up to room temperature, a refractory organic residue forms. The main product is hexamethylenetetramine molecule (HMT, $\mathrm{C}_{6} \mathrm{H}_{12} \mathrm{~N}_{4}$ ) which can represent up to $\sim 50 \mathrm{wt} \%$ of the residue as determined by infrared spectroscopy (Bernstein et al., 1995; Cottin et al., 2001; Muñoz Caro and Schutte, 2003; Vinogradoff et al., $2015,2013,2011)$. Of note, irradiation itself is not required to form HMT. The detailed mechanism of HMT formation shows that the molecule is actually formed during the heating of the ice analog from three molecules: formaldehyde, ammonia and formic acid (Vinogradoff et al., 2012), which are molecules commonly observed in interstellar ices of molecular clouds and young stellar objects (Boogert et al., 2008; Gibb et al., 2004). Although HMT forms at relatively high temperature in laboratory experiments $(280 \mathrm{~K})$, it has been suggested that on longer timescales, it may form at temperatures as low as $200 \mathrm{~K}$ in protoplanetary or cometary environments (Vinogradoff et al., 2013). HMT has not been observed in astrophysical environments because it does not have rotational mode for gas phase detection and because its IR bands are overlapped with silicate bands in solid phase (Bowey et al., 1998).

There are several scenarios that could account for the accretion of HMT in chondrites. First, if HMT precursors-bearing ices were heated above $200 \mathrm{~K}$ in the protoplanetary disk, HMT might form (Vinogradoff et al., 2015, 2013). Above $200 \mathrm{~K}$, the water is sublimated but HMT can remain stable up to $400-500 \mathrm{~K}$ (Vinogradoff et al., 2012), absorbed onto silicate grains or as individual solid grains for instance. HMT molecules could have then survived in the protoplanetary disk and may have been accreted on asteroids. Another possibility is that ice mixtures containing water and the HMT precursors were directly co-accreted in asteroids (Le Guillou and Brearley, 2014). Over the course of the warming of the asteroids, at temperature below the water melting point $(<250-270 \mathrm{~K})$, reactions similar to the one observed in annealing ice experiments could occur and lead to the formation of HMT, at the expense of formaldehyde and ammonia. Given that up to $15 \mathrm{wt} \%$ of water is present in chondrites, if HMT precursors are indeed associated with water ice, it is possible that a significant amount of HMT could be formed in the very early stages of the asteroids life. In any case, the refractory organic residues of interstellar ice experiments, including HMT, are likely to be present in primitive bodies (Caselli and Ceccarelli, 2012; Ciesla and Sandford, 2012; Danger et al., 2016; Gudipati et al., 2015).

Here, we use HMT as a representative, simple molecule, resulting from interstellar ice evolution. We conducted experiments for different durations (up to 31 days) under hydrothermal conditions typical of those that existed on asteroids, i.e. at $150{ }^{\circ} \mathrm{C}(423 \mathrm{~K})$ under alkaline $\mathrm{pH}$ (Brearley, 2006). Both soluble and insoluble experimental products were characterized by gas-chromatography coupled to mass spectrometry (GC-MS), Fourier transform infrared spectroscopy (FTIR) and synchrotron-based X-ray absorption near edge structure (XANES) spectroscopy. Altogether, the present study illustrates the diversity of molecules that can derive from a simple soluble organic molecule under hydrothermal conditions, including insoluble macromolecules. We discuss the significance of the present results for the origin of chondritic OM.

\section{Methods}

\subsection{Hydrothermal experiments and products extraction}

Hydrothermal experiments were carried out within Parr@ PTFE reactors maintained at $150{ }^{\circ} \mathrm{C} \sim 5$ bars (saturation vapor pressure) for different durations (2, 7, 20 and 31 days). HMT powder (> 99\% Sigma Aldrich) was mixed with bi-distilled water, previously mixed with $\mathrm{KOH}$ to adjust the $\mathrm{pH}$ at 10 , to obtain solutions at $0.7 \mathrm{M}$ $\left(\mathrm{mol} \mathrm{L}^{-1}\right)$. To note, this concentration is below the saturation point of HMT in water at room temperature $\left(6 \mathrm{~mol} \mathrm{~L}^{-1}\right)$. Bi-distilled water solution at $\mathrm{pH} 10$ was degassed with argon before experiments. $2 \mathrm{~mL}$ of these solutions were introduced into $12 \mathrm{~mL}$ PTFE reactors. PTFE reactors were closed under argon atmosphere (> 99.999\%; Air Liquide, ALPHAGAZ 1$)$ in a glove box $\left(<0.5 \mathrm{ppm} \mathrm{O}_{2}\right)$.

At the end of each experiment, solutions were centrifuged in Eppendorf bio-pur tubes $(2 \mathrm{~mL})$ for $6 \mathrm{~min}$ at $12,000 \mathrm{rpm}$. The $\mathrm{pH}$ at the end of each experiments was around 10 . These solutions were directly analyzed by XANES spectroscopy while liquid-liquid extractions were performed using $0.4 \mathrm{~mL}$ of dichloromethane (DCM) on $0.4 \mathrm{~mL}$ aliquots to perform GC-MS analyses (Fig. 1). Of note, no organic compounds were observed after 31 day-long blank experiments carried out with pure bi-distilled water.

An insoluble, dark brown solid material was recovered for experiments longer than 7 days. This IOM was washed twice with water, methanol, and DCM/methanol (1:1 vol/vol), as well as with a $\mathrm{HF} / \mathrm{HCl}$ solution $(3: 1 \mathrm{vol} / \mathrm{vol}, 12 \mathrm{M} / 3 \mathrm{M})$ for $24 \mathrm{~h}$. The IOM were then dried in an oven for 4 days at $60^{\circ} \mathrm{C}$ under primary vacuum before bulk elemental composition analyses and infrared and XANES spectroscopy experiments (Fig. 1).

\subsection{Elemental analysis}

The hydrogen, nitrogen and carbon contents of the IOM were determined using the Thermo-Fisher Flash 2000 CHNS-O analyzer operating at ISTeP (Paris, France). A mass of $0.7 \mathrm{mg}$ of IOM was combusted under oxygen/helium flux at $960^{\circ} \mathrm{C} . \mathrm{N}_{2}, \mathrm{CO}_{2}$, and $\mathrm{H}_{2} \mathrm{O}$ released by combustion were separated by a chromatography column and quantified using a thermal conductivity detector. Sulphanilamide $\left(\mathrm{C}_{6} \mathrm{H}_{8} \mathrm{~N}_{2} \mathrm{O}_{2} \mathrm{~S}\right)$ was used as a standard.

\subsection{Gas chromatography-mass spectrometry}

Gas Chromatography-Mass Spectrometry (GC-MS) analyses were carried out using the Agilent Technologies 6890N gas chromatograph coupled with an Agilent Technologies 5973 network mass spectrometer operating at METIS (Paris, France). The capillary column is a RTX-5Si/MS $(30 \mathrm{~m} \times 0.25 \mathrm{~mm}, 0.5 \mu \mathrm{m}$ film) coated with chemically bound Restek (low-polarity phase, suitable for semivolatile, hydrocarbon, amine, phenol compounds). The temperature 


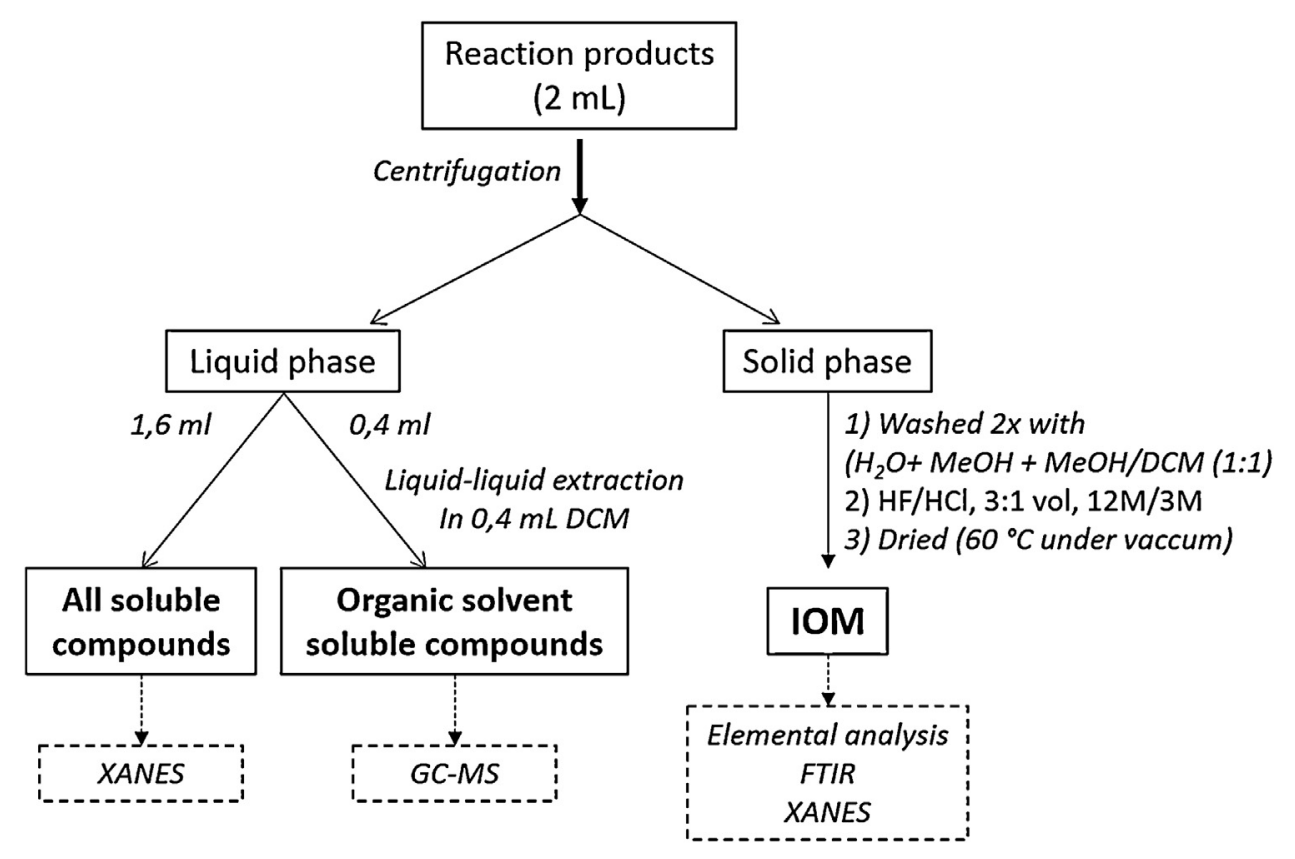

Fig. 1. Schematic representation of the preparation of experimental residues for GC-MS, IR and XANES analyses.

injection was $80^{\circ} \mathrm{C}$ in splitless mode and the GC oven program started at $50^{\circ} \mathrm{C}-320^{\circ} \mathrm{C}$ at $4{ }^{\circ} \mathrm{C} / \mathrm{min}$ with He as carrier gas. The solvent delay was as short as possible $(3 \mathrm{~min})$ and no derivatization was performed. Measurements were performed using an electron energy of $70 \mathrm{eV}$, an ion source temperature of $220^{\circ} \mathrm{C}$ and a scanning rate of $2.24 \mathrm{scan} \mathrm{s}^{-1}$ from 35 to $700 \mathrm{~m} / \mathrm{z}$. Products were identified using the NIST database. Data processing was done using the OpenChrom software, namely subtraction of the solvent background (DCM) taken at 3.8 min followed by an automatic peak detection using the mass selective detector (MSD) first derivative process (signal to noise ratios $>3$ ) and then each peak is integrated using the MSD integrator option. This procedure allowed quantifying a molecular size index in our experiments that corresponds to the ratio between the integrated area of all peaks appearing between 25 and 54 min (hereafter called "heavy compounds", HC) and the integrated area of all peaks appearing between 5 and 25 min (hereafter called "light compounds", LC).

\subsection{FTIR}

FTIR analyses were performed using the Vertex 70 spectrometer (Bruker) operating at the MNHN (Paris, France). Less than $0.5 \mathrm{mg}$ of powdered sample was pressed onto the diamond crystal surface using a single reflection in the attenuate total resonance (ATR) device, ATR-quest (Specac). The absorption of the infrared beam by the samples was measured from 370 to $4000 \mathrm{~cm}^{-1}$ with a spectral resolution of $4 \mathrm{~cm}^{-1}$. Spectra were accumulated 96 times (vs. 128 for the background to ensure a good signal to noise ratio). Each IR spectrum was corrected with a baseline generated by the Bruker Opus software, integrated and normalized to its total area.

\subsection{XANES spectroscopy}

\subsubsection{XANES data acquisition procedure}

XANES data were collected on the 10ID-1 STXM beamline (Kaznatcheev et al., 2007) at the Canadian Light Source (CLS) and on the HERMES STXM beamline (Belkhou et al., 2015; Swaraj et al., 2017) at the synchrotron SOLEIL. At CLS, a $100 \mathrm{~nm}$ thick titanium filter is used to remove the contribution of second order light while at SOLEIL, beamline optical elements are exposed to a continuous flow of pure $\mathrm{O}_{2}$ to remove carbon contamination. Microscope chambers were pumped down to less than 100 mTorr after sample insertion. Energy calibration is done before measurements using the well-resolved 3p Rydberg peak of gaseous $\mathrm{CO}_{2}$ at $294.96 \mathrm{eV}$ for the $\mathrm{C}$ K-edge and using the $1 \mathrm{~s} \rightarrow \pi^{*}$ photo-absorption resonance of gaseous $\mathrm{N}_{2}$ at $400.8 \mathrm{eV}$ for the $\mathrm{N} \mathrm{K-edge.}$

For the present study, samples were deposited on $\mathrm{Si}_{3} \mathrm{~N}_{4}$ windows ( $50 \mathrm{~nm}$ thick membrane). Image stacks were collected with energy increments of $1 \mathrm{eV}$ over the $250-450 \mathrm{eV}$ energy range to measure $\mathrm{N} / \mathrm{C}$ values, following the procedure described in Alleon et al., (2015). Additional image stacks were collected with energy increments of $0.1 \mathrm{eV}$ over the carbon $(270-350 \mathrm{eV})$ and the nitrogen (390-420 eV) absorption ranges to gain insights on carbon and nitrogen speciation. Data were collected with a dwell time of one millisecond per pixel to prevent irradiation damages as recommended by Wang et al. (2009) and processed using the aXis2000 software (ver. $2.1 \mathrm{n}$ ). The C- and N-XANES spectra shown here correspond to homogeneous areas of several tens of squared micrometers each.

\subsubsection{XANES data deconvolution procedure}

The same deconvolution procedure in three steps was applied to all C-XANES spectra: i) background subtraction, ii) normalization to the total carbon content, and iii) spectral fitting using Gaussian functions. Background subtraction consisted in the subtraction of a linear regression over the $270-282 \mathrm{eV}$ energy range. Then, following Barré et al. (2016) and Alleon et al. (2017), C-XANES spectra were normalized to their area between $280 \mathrm{eV}$ and $291.5 \mathrm{eV}$ and N-XANES spectra were normalized to their area between 395 and 406.5, thereby ensuring chemical consistency (a spectrum showing a more prominent absorption at a given energy must have a less intense absorption at other energies).

After normalization, Gaussian functions with a given full-width at half maximum $(0.6 \mathrm{eV})$ were used for C-XANES signal deconvolution. Their positions were fixed following Urquhart et al. (1999), Dhez et al. (2003) and De Gregorio et al. (2010) (see Table 1). The height of the Gaussian curves were used as a proxy of the abundance of the functional group absorption. Due to overlapping energies of several resonances, absorption peaks at the $\mathrm{N}$ K-edge 
Table 1

Positions and peak attributions for the deconvolution of the C-XANES spectra, from Urquhart et al. (1999), Dhez et al. (2003) and De Gregorio et al. (2010).

\begin{tabular}{ll}
\hline X-Ray absorption $(\mathrm{eV})$ & Functional groups \\
\hline 284.4 & Quinones \\
$284.7 ; 285 ; 285.4$ & Aromatics; olefins \\
285.8 & Imines \\
$286.2 ; 286.6 ; 286.8$ & Ketones; phenols; nitriles \\
$287.6 ; 287.9$ & Aliphatics \\
288.2 & Amides \\
288.55 & Carboxyls; esters; acetals \\
289 & Aldehydes \\
289.4 & Hydroxyls \\
289.9 & Aliphatics; carbamoyls \\
290.3 & Carbonates \\
\hline
\end{tabular}

cannot be univocally assigned to given functional groups. Still, the $\mathrm{N}$ local coordination can be partly inferred based on the energy of absorption features: imine, nitrile and pyridinic $\mathrm{N}$ will generate absorption features below $400 \mathrm{eV}$, while absorption features above $400 \mathrm{eV}$ will indicate the presence of amide, nitro and pyrrolic $\mathrm{N}$ (Leinweber et al., 2007; Myneni, 2002).

Following previous studies (Alleon et al., 2016b, 2017; Bernard et al., 2012, 2015; Le Guillou et al., 2013, 2014; Vinogradoff et al., 2017), semi-quantitative parameters were extracted from the XANES spectra: 1) the aromatic/olefin/imine index that corresponds to the relative content of Aromatic $C, C=C$ and $C=N$ (i.e. the sum of the areas of the Gaussian functions used to deconvolve the absorption signal in the range $284.4-285.8 \mathrm{eV}$ ), 2) the ketone/phenol/nitrile index that corresponds to the relative content of $\mathrm{C}=\mathrm{O}$, Aromatic- $\mathrm{OH}$ and $\mathrm{C} \equiv \mathrm{N}$ (i.e. the sum of the areas of the Gaussian functions used to deconvolve the absorption signal in the range $286.2-286.8 \mathrm{eV}$ ) and 3), the amide/carboxyl/ester/acetal index that corresponds to the relative content of $\mathrm{N}-\mathrm{C}=\mathrm{O}$ and $\mathrm{COOH} / \mathrm{COOR}$ (i.e. the sum of the areas of the Gaussian functions used to deconvolve the absorption signal in the range 288.2$288.55 \mathrm{eV}$ ). These values carry a degree of uncertainty of $\pm 10 \%$.

\section{Results}

\subsection{Evolution of the soluble compounds}

\subsubsection{XANES data}

XANES spectra of the starting and of the residual solutions were collected prior any extraction. The C-XANES spectrum (Fig. 2b) of the starting HMT solution $(0.7 \mathrm{M})$ exhibits a broad absorption band centered at $290 \mathrm{eV}$, attributed to the $1 \mathrm{~s} \rightarrow \sigma^{*}$ electronic transitions of amine (C-N) groups (Myneni, 2002; Solomon et al., 2009). The $\mathrm{N}$-XANES spectrum (Fig. 2c) of the starting HMT solution exhibits a broad absorption feature centered at $406.8 \mathrm{eV}$ with two peaks at 399.2 and $401.2 \mathrm{eV}$. Given the HMT structure, these peaks might be assigned to tertiary amines functions $\left(\mathrm{N}-\left(\mathrm{CH}_{2}\right)_{3}\right)$ involved in a cyclic structure. Although HMT exhibits an initial N/C value of 0.57 , the mean $\mathrm{N} / \mathrm{C}$ value of all the residual solutions is 0.27 , thereby highlighting a chemical evolution of HMT during experiments.

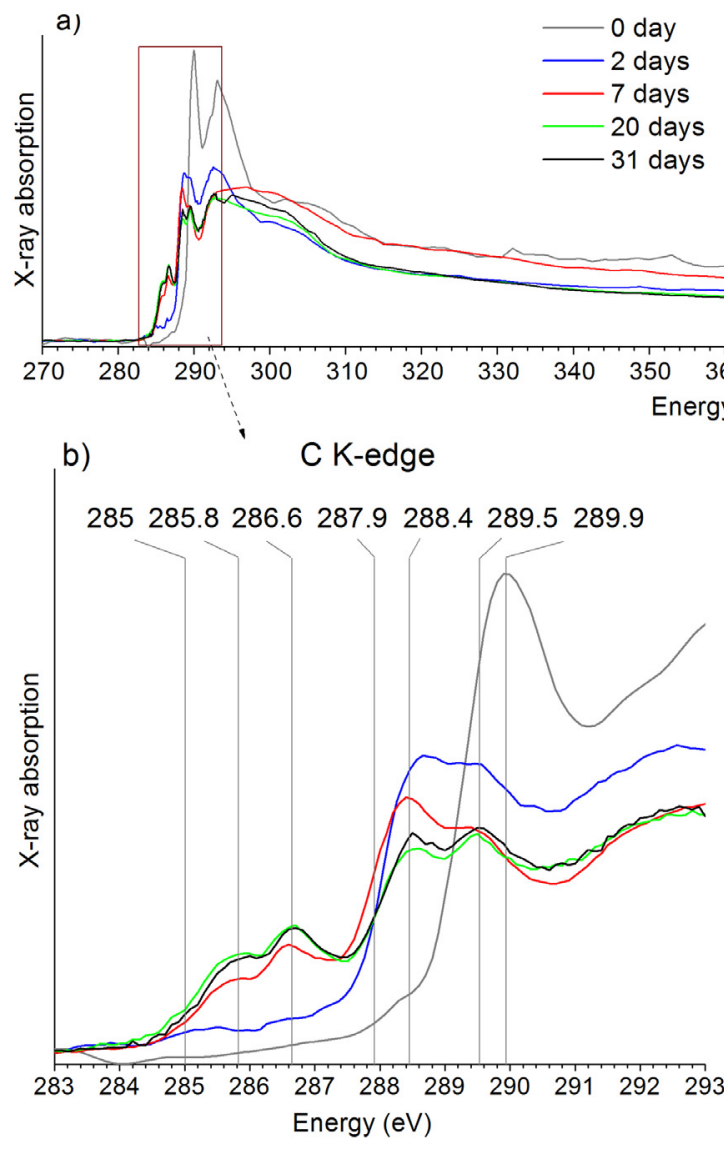

$N / C=0,57$
$N / C=0,25$
$N / C=0,28$
$N / C=0,27$
$N / C=0,28$

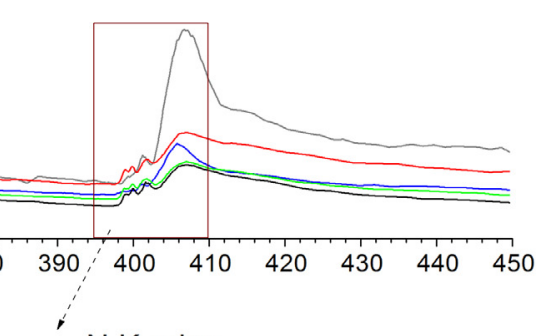

c)

N K-edge

$398.9399 .2399 .9401 .2401 .8 \quad 405,7 \quad 406,8$

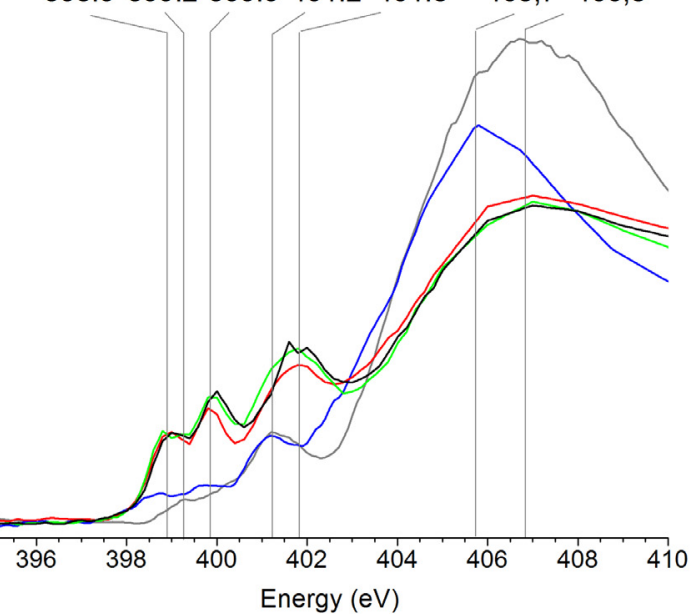

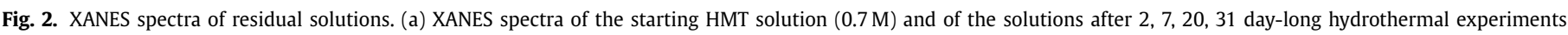

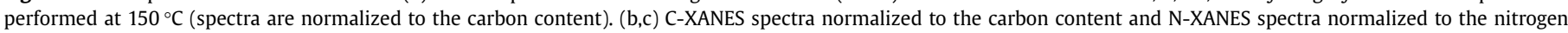

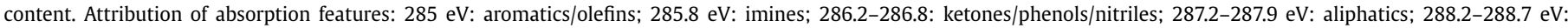

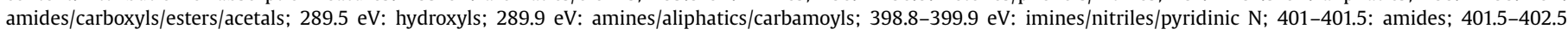
$\mathrm{eV}$ : pyrroles. 

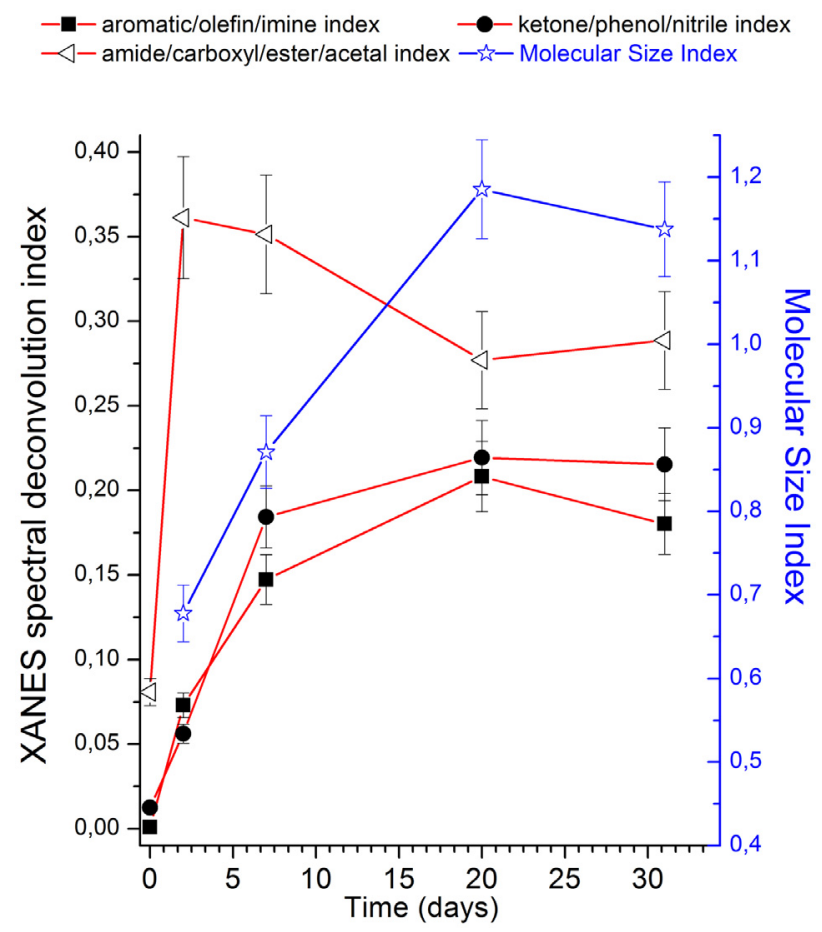

Fig. 3. Evolution of the aromatic/olefin/imine index, the ketone/phenol/nitrile index, the amide/carboxyl/ester/acetal index and the molecular size index of the solutions as a function of experimental duration.

After 2 days at $150^{\circ} \mathrm{C}$, the residual solution exhibits a C-XANES spectrum with two main peaks at 288.4 and $289.5 \mathrm{eV}$, attributed to the presence of amide $(\mathrm{N}-\mathrm{C}=\mathrm{O})$, acetal $(\mathrm{O}-\mathrm{C}-\mathrm{O})$, ester $(\mathrm{O}=\mathrm{C}-\mathrm{O}-\mathrm{R})$ and/or carboxyl $(\mathrm{O}=\mathrm{C}-\mathrm{OH})$ groups and to the presence of hydroxyl groups (C-OH), respectively (Lessard et al., 2007; Robin et al., 2015; Rouchon and Bernard, 2015). Two additional, less intense absorption features can be observed at $285.8 \mathrm{eV}$, corresponding to $1 \mathrm{~s} \rightarrow$ $\pi^{*}$ electronic transitions of imine $(\mathrm{C}=\mathrm{N})$ groups, and at $286.6 \mathrm{eV}$ attributed to $1 \mathrm{~s} \rightarrow \pi^{*}$ electronic transitions of ketone $(C=0)$, phenol $(\mathrm{Ar}-\mathrm{OH})$ and/or nitrile $(\mathrm{C} \equiv \mathrm{N})$ groups (Dhez et al., 2003; Hitchcock et al., 2005). The N-XANES spectrum of this residual solution exhibits two peaks at 398.9 and $399.9 \mathrm{eV}$, likely corresponding to
$1 \mathrm{~s} \rightarrow \pi^{*}$ electronic transitions of imine $(\mathrm{C}=\mathrm{N})$, nitrile $(\mathrm{C} \equiv \mathrm{N})$ and/or pyrrole/pyrimidine groups and a peak at $401.2 \mathrm{eV}$, related to the contribution of $1 \mathrm{~s} \rightarrow \pi^{*}$ transitions in amine and/or amide groups (Alleon et al., 2017, 2016a; Leinweber et al., 2007; Myneni, 2002).

With increasing experimental duration (from 2 to 20 days), the relative concentrations of aromatic/imine carbons and ketone/phenol/nitrile carbons significantly increase (peaks at 285.8 and $286.6 \mathrm{eV}$ ) while the relative concentrations of amide/carboxyl/ester/acetal and hydroxyl carbons slightly decrease (peaks at 288.4 and $289.5 \mathrm{eV}$ ) in the residual solution (Figs. 2 and 3). Consistently, the contribution of the broad absorption feature at $406.8 \mathrm{eV}$ decreases while the contributions of the imine/nitrile/pyrrole/pyrimidine groups (peaks at 398.9 and $399.9 \mathrm{eV}$ ) and of the amide/amine/pyrazole groups (peaks at 401.2 and $401.8 \mathrm{eV}$ ) increase. After 20 days, the mean molecular composition of the organic compounds in solution stops evolving (Fig. 3).

\subsubsection{GC-MS data}

GC-MS data were collected on the DCM liquid-liquid extracts. The gas chromatogram of the DCM extract (Fig. 4) of the starting HMT solution $(0.7 \mathrm{M})$ only displays the HMT peak at $20.73 \mathrm{~min}$ $(\mathrm{m} / \mathrm{z} 140$ ). This peak is still observed after 2 and 7 days (very small peak) of hydrothermal alteration but no more after 20 days, indicating that the total degradation of HMT takes between 7 and 20 days at $150{ }^{\circ} \mathrm{C}$ (Fig. 4). Concomitant with the degradation of HMT, the number of soluble organic compounds (number of peaks in the chromatogram) increases with increasing experimental duration (Fig. 4).

Light compounds -LC- with $\mathrm{m} / \mathrm{z}$ up to 136 can be identified between 5 and $25 \mathrm{~min}$ and correspond mainly to three families of nitrogen-rich molecules (Fig. 4, Table 2): pyridine derivative molecules (6-membered ring molecules $-\mathrm{C}_{5} \mathrm{H}_{5} \mathrm{~N} \pm$ alkyl substituents), imidazole/pyrazole derivative molecules (5-membered ring molecules $-\mathrm{C}_{3} \mathrm{H}_{4} \mathrm{~N}_{2} \pm$ alkyl substituents), and pyrazine derivative molecules (6-membered ring molecules $-\mathrm{C}_{4} \mathrm{H}_{4} \mathrm{~N}_{2} \pm$ alkyl substituents). Oxygen-bearing products are also observed, such as $\mathrm{N}-\mathrm{N}$-dimethyl formamide $\left(\mathrm{C}_{3} \mathrm{H}_{7} \mathrm{NO}\right.$ - first peak at $\left.5.37 \mathrm{~min}\right)$ that form during the first 2 days of hydrothermal alteration, and pyrazolidinones and imidazolidinones (i.e. pyrazoles or imidazoles with an additional carbonyl group) that require longer times to form (they are observed after 20 days) (Table 2).

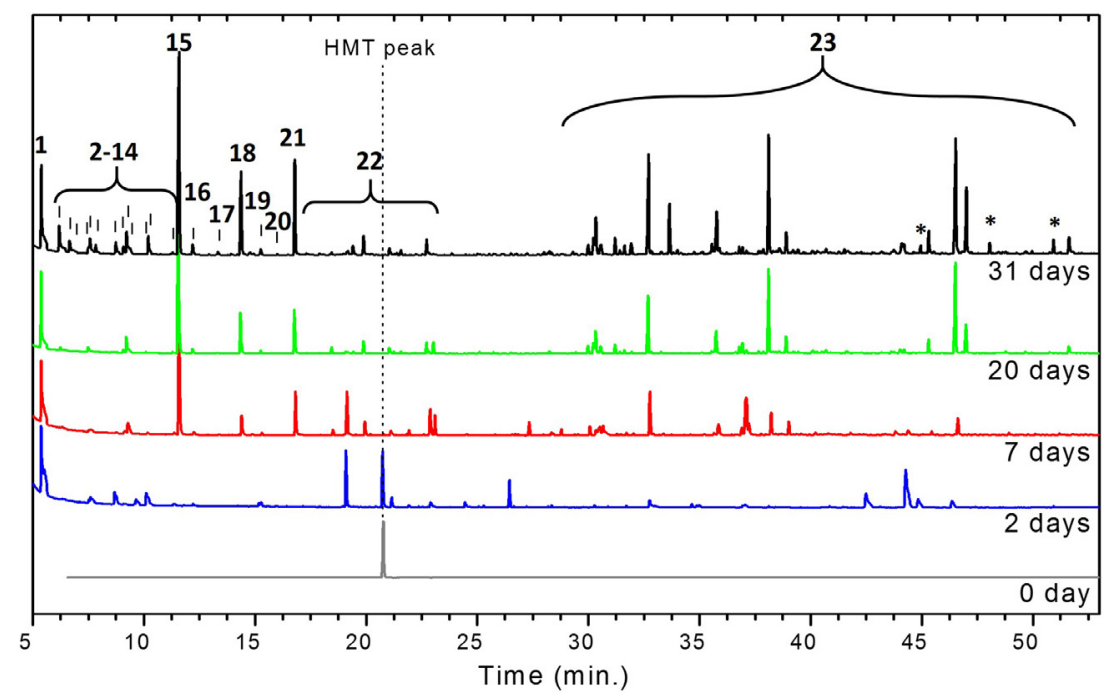

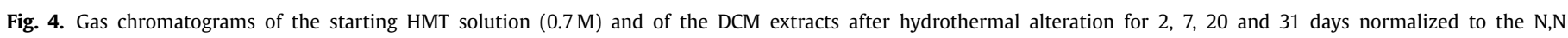

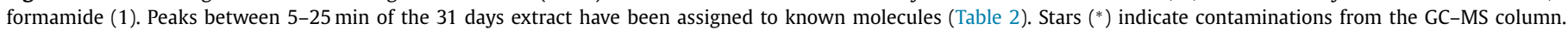


Table 2

Nature of the organic molecules identified using GC-MS within the DCM extract of the HMT solution ( $0.7 \mathrm{M})$ after 31 days of hydrothermal alteration at $150^{\circ} \mathrm{C}$. The retention time, the molecular ion $(\mathrm{m} / \mathrm{z}$ ), the $\mathrm{m} / \mathrm{z}$ of the main fragments (sorted by decreasing intensity $-m / z$ ) and their possible assignments are reported for each "light compound" observed.

\begin{tabular}{|c|c|c|c|c|c|}
\hline \multirow{2}{*}{ Number } & \multirow{2}{*}{ Retention time } & \multirow{2}{*}[\mathrm{M}+]{$\mathrm{m} / \mathrm{z}$} & \multirow{2}{*}{$\begin{array}{l}\text { Main fragments* } \\
m / z\end{array}$} & \multicolumn{2}{|l|}{ Possible assignment } \\
\hline & & & & Name & Formula \\
\hline 1 & 5.37 & 73 & 44,42 & $\mathrm{~N}-\mathrm{N}$-dimethyl formamide & $\mathrm{C}_{3} \mathrm{H}_{7} \mathrm{NO}$ \\
\hline 2 & 6.18 & 98 & $97,42,56$ & C2-methyl, 2-pyrazoline/imidazoline, & $\mathrm{C}_{5} \mathrm{H}_{10} \mathrm{~N}_{2}$ \\
\hline 3 & 6.65 & 96 & $95,81,68,54$ & C2-alkyl imidazole or pyrazole & $\mathrm{C}_{5} \mathrm{H}_{8} \mathrm{~N}_{2}$ \\
\hline 4 & 6.94 & 83 & 56 & 1-methyl-1H-1,2,4-triazole & $\mathrm{C}_{3} \mathrm{H}_{5} \mathrm{~N}_{3}$ \\
\hline 5 & 7.48 & 93 & $92,66,65,39$ & Pyridine, 3-methyl & $\mathrm{C}_{6} \mathrm{H}_{7} \mathrm{~N}$ \\
\hline 6 & 7.56 & 96 & $98,42,68,54$ & C2-alkyl imidazole or pyrazole & $\mathrm{C}_{5} \mathrm{H}_{8} \mathrm{~N}_{2}$ \\
\hline 7 & 7.82 & 112 & $97,111,42,56$ & 2-Pyrazoline, 1,3,4-trimethyl- & $\mathrm{C}_{6} \mathrm{H}_{12} \mathrm{~N}_{2}$ \\
\hline 8 & 8.73 & 112 & $97,111,83,42$ & 2-Pyrazoline, 3-ethyl,1-methyl & $\mathrm{C}_{6} \mathrm{H}_{12} \mathrm{~N}_{2}$ \\
\hline 9 & 9.07 & 108 & $42,40,39$ & Pyrazine, 2,6-dimethyl & $\mathrm{C}_{6} \mathrm{H}_{8} \mathrm{~N}_{2}$ \\
\hline 10 & 9.22 & 82 & $54,42,81,40$ & 1H-imidazole, 1-methyl & $\mathrm{C}_{4} \mathrm{H}_{6} \mathrm{~N}_{2}$ \\
\hline 11 & 9.39 & 110 & $95,109,42$ & C3-alkyl imidazole or pyrazole & $\mathrm{C}_{6} \mathrm{H}_{10} \mathrm{~N}_{2}$ \\
\hline 12 & 10.1 & 107 & $106,79,66,92$ & C2-alkyl pyridine & $\mathrm{C}_{7} \mathrm{H}_{9} \mathrm{~N}$ \\
\hline 13 & 10.18 & 110 & $109,68,95,42$ & C3-alkyl imidazole or pyrazole & $\mathrm{C}_{6} \mathrm{H}_{10} \mathrm{~N}_{2}$ \\
\hline 14 & 11.28 & 107 & $106,79,92,77$ & C2-alkyl pyridine & $\mathrm{C}_{7} \mathrm{H}_{9} \mathrm{~N}$ \\
\hline 15 & 11.55 & 96 & $95,68,42,81$ & Imidazole-1,4-dimethyl & $\mathrm{C}_{5} \mathrm{H}_{8} \mathrm{~N}_{2}$ \\
\hline 16 & 12.18 & 122 & $42,81,109$ & Pyrazine, trimethyl & $\mathrm{C}_{7} \mathrm{H}_{10} \mathrm{~N}_{2}$ \\
\hline 17 & 13.33 & 99 & $98,44,42$ & Pyrrolidinone, -methyl & $\mathrm{C}_{5} \mathrm{H}_{9} \mathrm{NO}$ \\
\hline 18 & 14.36 & 96 & $95,68,42,56$ & C2-alkyl imidazole or pyrazole & $\mathrm{C}_{5} \mathrm{H}_{8} \mathrm{~N}_{2}$ \\
\hline 19 & 15.25 & 136 & $54,42,39$ & Pyrazine tetramethyl & $\mathrm{C}_{8} \mathrm{H}_{12} \mathrm{~N}_{2}$ \\
\hline 20 & 15.99 & 114 & $44,113,42$ & 2-imidazolidinone, 1.3-dimethyl & $\mathrm{C}_{5} \mathrm{H}_{10} \mathrm{~N}_{2} \mathrm{O}$ \\
\hline 21 & 16.79 & 110 & $109,95,68,42$ & C3-alkyl imidazole or pyrazole & $\mathrm{C}_{6} \mathrm{H}_{10} \mathrm{~N}_{2}$ \\
\hline 22 & $17.2-22$ & 110,124 & - & C3/C4-alkyl imidazole or pyrazole & $\mathrm{C}_{6} \mathrm{H}_{10} \mathrm{~N}_{2}$ \\
\hline 23 & $25-54$ & & & Heavy compounds $(\mathrm{HC})$ & $\mathrm{C}_{7} \mathrm{H}_{12} \mathrm{~N}_{2}$ \\
\hline
\end{tabular}

Heavy compounds -HC- with $m / z$ comprised between 136 and 254 can be observed at retention times between 25 and 55 min (Fig. 4). Although the exact nature of these compounds is not readily assigned, they exhibit characteristic fragments of 6/5-membered ring pyridine/imidazole/pyrazine. They thus could be further derivatives of the pyridine/imidazole/pyrazine LC (with additional alkyl or $\mathrm{CO}_{2}$ or $\mathrm{NH}_{2}$ substituents) or pyridine/imidazole/pyrazine polycyclic compounds. Of note, the abundance of HC increases with increasing hydrothermal alteration duration (Figs. 3 and 4). In fact, the molecular size index (i.e. the HL/LC ratio) increases with experimental duration up to 20 days (Fig. 3).

\subsection{Formation of an insoluble material}

A dark brown solid material, representing less than $1 \%$ wt of the initial HMT, forms during experiments longer than 7 days. This material being insoluble in water, $\mathrm{MeOH}$ and DCM is logically called IOM hereafter. Elemental analyses conducted on the IOM from the 31 day-long experiment reveals that it contains $53.4 \pm 0.2 \mathrm{wt} \%$ of $\mathrm{C}$, $5.3 \pm 0.01 \mathrm{wt} \%$ of $\mathrm{H}, 18.7 \pm 0.1 \mathrm{wt} \%$ of $\mathrm{N}$ and $22.6 \pm 0.2 \mathrm{wt} \%$ of 0 , i.e. its formula can be written $\mathrm{C}_{100} \mathrm{H}_{120} \mathrm{~N}_{30} \mathrm{O}_{31}$.

The IOMs from the 7,20 and 31 day-long experiments are spectroscopically very similar (Figs. 5 and 6), thereby highlighting a similar chemical composition. Their IR spectra display stretching vibrations of $\mathrm{NH}$ and $\mathrm{OH}$ bonds (3600-3000 $\mathrm{cm}^{-1}$ ), $\mathrm{C}-\mathrm{H}$ bonds $\left(2850-2950 \mathrm{~cm}^{-1}\right), \quad \mathrm{C}=\mathrm{C}$ or $\mathrm{C}=\mathrm{N}$ bonds $(1550-$

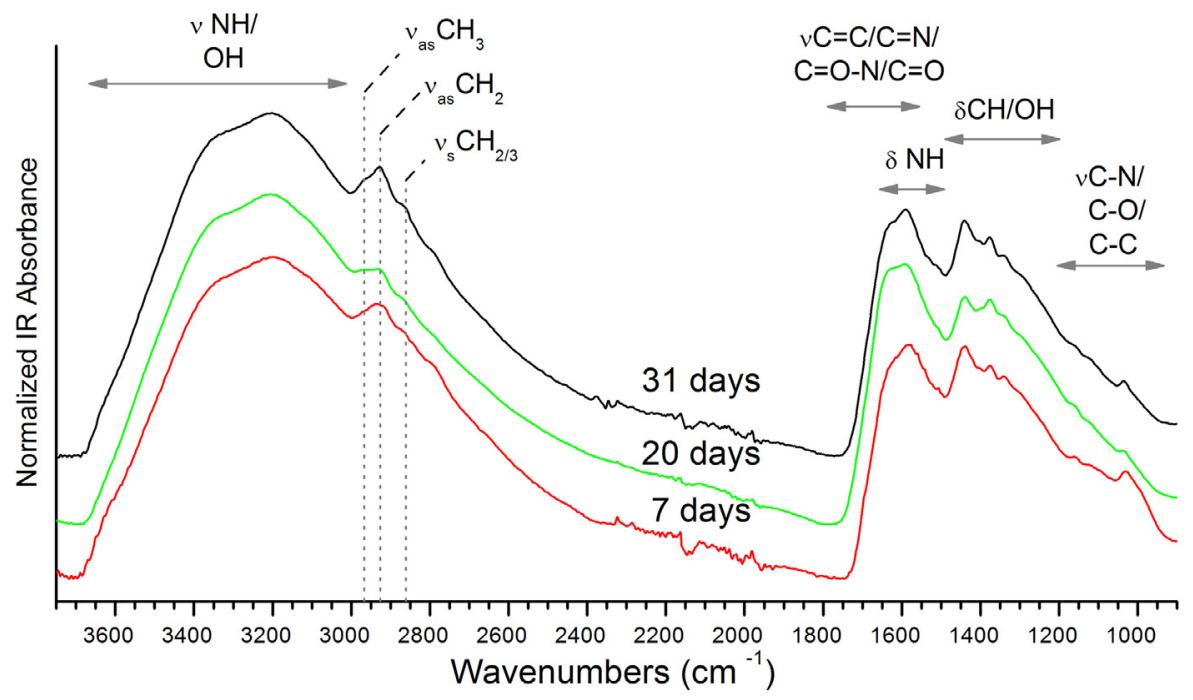

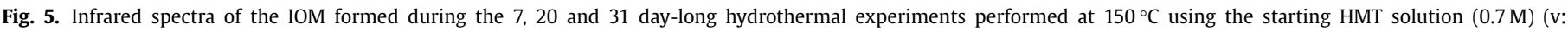
stretching bands, as: asymmetric mode, s: symmetric mode, $\delta$ : bending bands). 


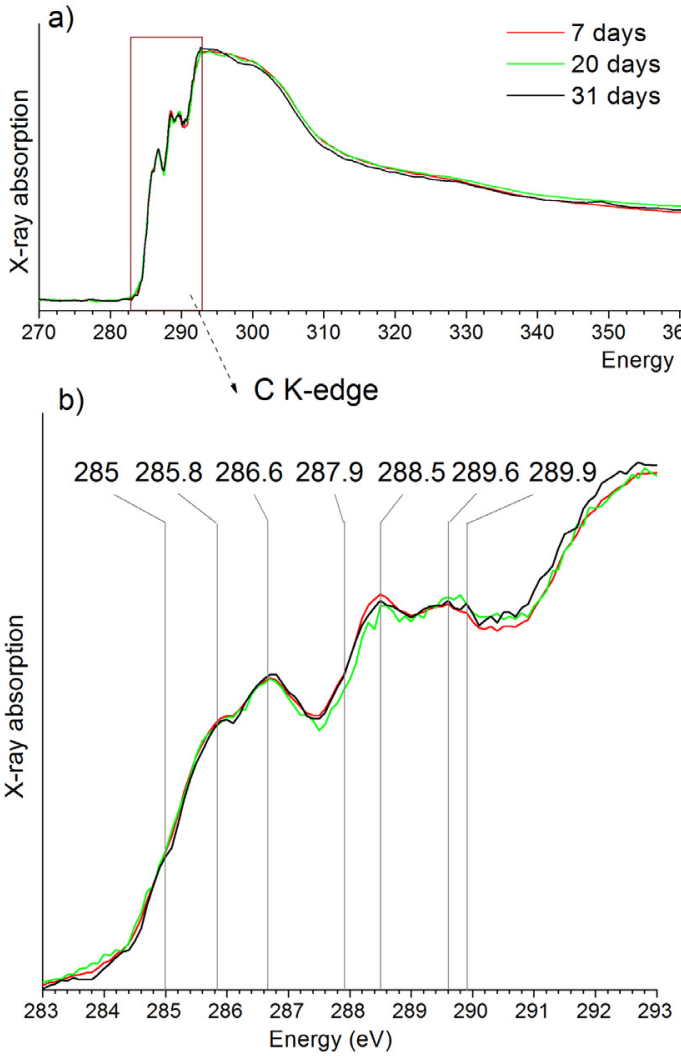

$\mathrm{N} / \mathrm{C}=0,28$

$\mathrm{N} / \mathrm{C}=0,29$

$\mathrm{N} / \mathrm{C}=0,28$

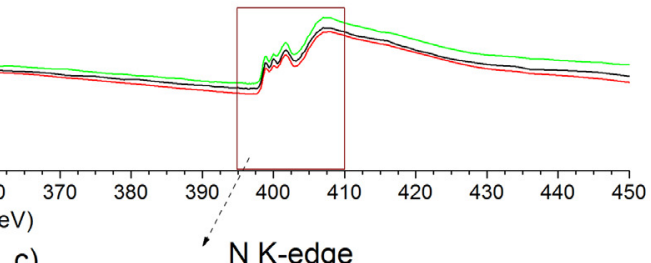

c)

N K-edge

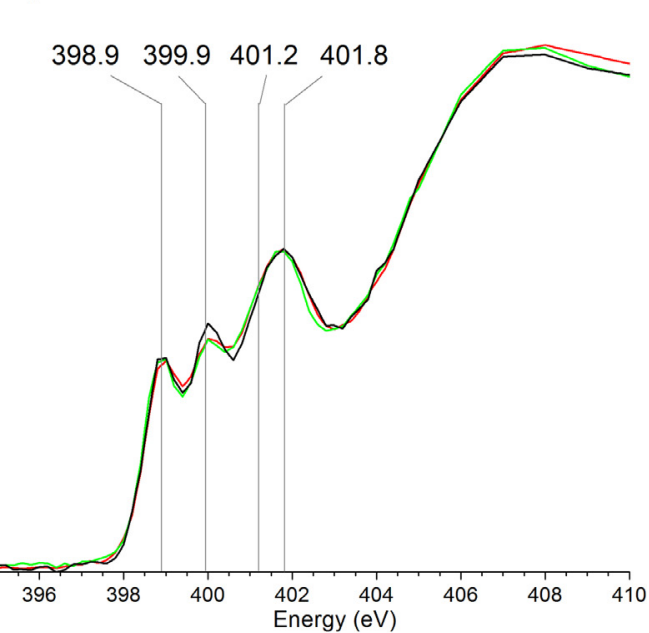

Fig. 6. XANES spectra of IOM. (a) XANES spectra of the IOM formed after 7, 20, 31 day-long hydrothermal experiments performed at $150{ }^{\circ} \mathrm{C}$ (spectra are normalized to the carbon content). (b,c) C-XANES spectra normalized to the carbon content and N-XANES spectra normalized to the nitrogen content. Attribution of absorption features: $285 \mathrm{eV}$ : aromatics/olefins; $285.8 \mathrm{eV}$ : imines; 286.2-286.8: ketones/phenols/nitriles; 287.2-287.9 eV: aliphatics; 288.2-288.7 eV: amides/carboxyls/esters/acetals; 289.5 eV: hydroxyls; $289.9 \mathrm{eV}$ : amines/aliphatics/carbamoyls; 398.8-399.9 eV: imines/nitriles/pyridinic N; 401-401.5: amides; 401.5-402.5 eV: pyrroles.

$\left.1620 \mathrm{~cm}^{-1}\right)$, and $\mathrm{C}=\mathrm{O} / \mathrm{C}=\mathrm{O}-\mathrm{N}$ bonds $\left(1650-1750 \mathrm{~cm}^{-1}\right)$, and bending vibrations of $\mathrm{NH}$ bonds $\left(1600-1500 \mathrm{~cm}^{-1}\right), \mathrm{C}-\mathrm{H}$ or $\mathrm{OH}$ bonds (below $1500 \mathrm{~cm}^{-1}$ ), together with stretching vibrations of $\mathrm{C}-\mathrm{O}$ and $\mathrm{C}-\mathrm{N}$ bonds $\left(900-1200 \mathrm{~cm}^{-1}\right.$ ) (Coates, 2006; Colthup, 1950). The C-XANES spectra of these IOMs (Fig. 6b) reveal the presence of aromatic or olefin $(285 \mathrm{eV})$, imine $(285.8 \mathrm{eV})$, ketone/phenol/nitrile $(286.6 \mathrm{eV})$, carboxyl/ester/acetal $(288.5 \mathrm{eV})$ and hydroxyl $(289.6 \mathrm{eV})$ groups. Peaks at 398.9 and $399.9 \mathrm{eV}$ observed in the N-XANES spectra support the presence of imine/nitrile and/or pyrrole/pyrimidine compounds, while the peaks at 401.2 and $401.8 \mathrm{eV}$ indicate the presence of amide/pyrazole compounds. $\mathrm{N} / \mathrm{C}$ values of 0.28 are estimated for these IOMs based on XANES data.

\section{Discussion}

The present hydrothermal alteration experiments show that, within a few days, HMT may evolve into (1) a very diverse suite of soluble compounds, including $\mathrm{N}-\mathrm{N}$-dimethyl formamide and $\mathrm{N}$ rich heterocyclic compounds (> 150 species after 31 days), and (2) a polymeric $\mathrm{N}$-rich IOM that forms after only 7 days of experiment (Fig. 7).

\subsection{Formation of a diverse suite of new soluble compounds}

HMT is formed from formaldehyde and ammonia and also decomposes, in water at temperature $>70^{\circ} \mathrm{C}$, into six molecules of formaldehyde and four of ammonia (Blažzević et al., 1979; Meissner et al., 1954). The exact kinetics of HMT decomposition in water remains unknown. Our data show that HMT does not persist much

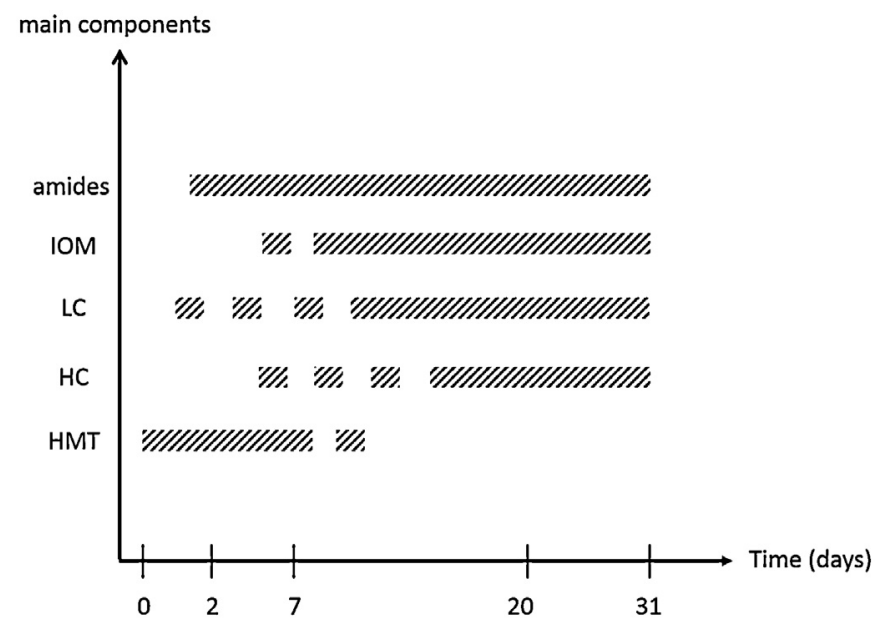

Fig. 7. Schematic representation of the detection of HMT, LC, HC, IOM and amides (mainly $\mathrm{N}, \mathrm{N}$-dimethylformamide) in experimental residues as a function of experimental duration.

longer than 7 days at $150{ }^{\circ} \mathrm{C}$ in alkaline solution, suggesting that HMT decomposition is instantaneous on asteroidal time scales.

In parallel, the present results evidence that the products of HMT decomposition can react to form a diversity of organic compounds under hydrothermal conditions typical of asteroids. In particular, numerous N-rich compounds form ( $>150$ species after 31 days, with $\mathrm{m} / \mathrm{z}$ comprised between 59 and 254), likely through chain reactions (Fig. 8). Note that the $\mathrm{N} / \mathrm{C}$ of the reaction products 


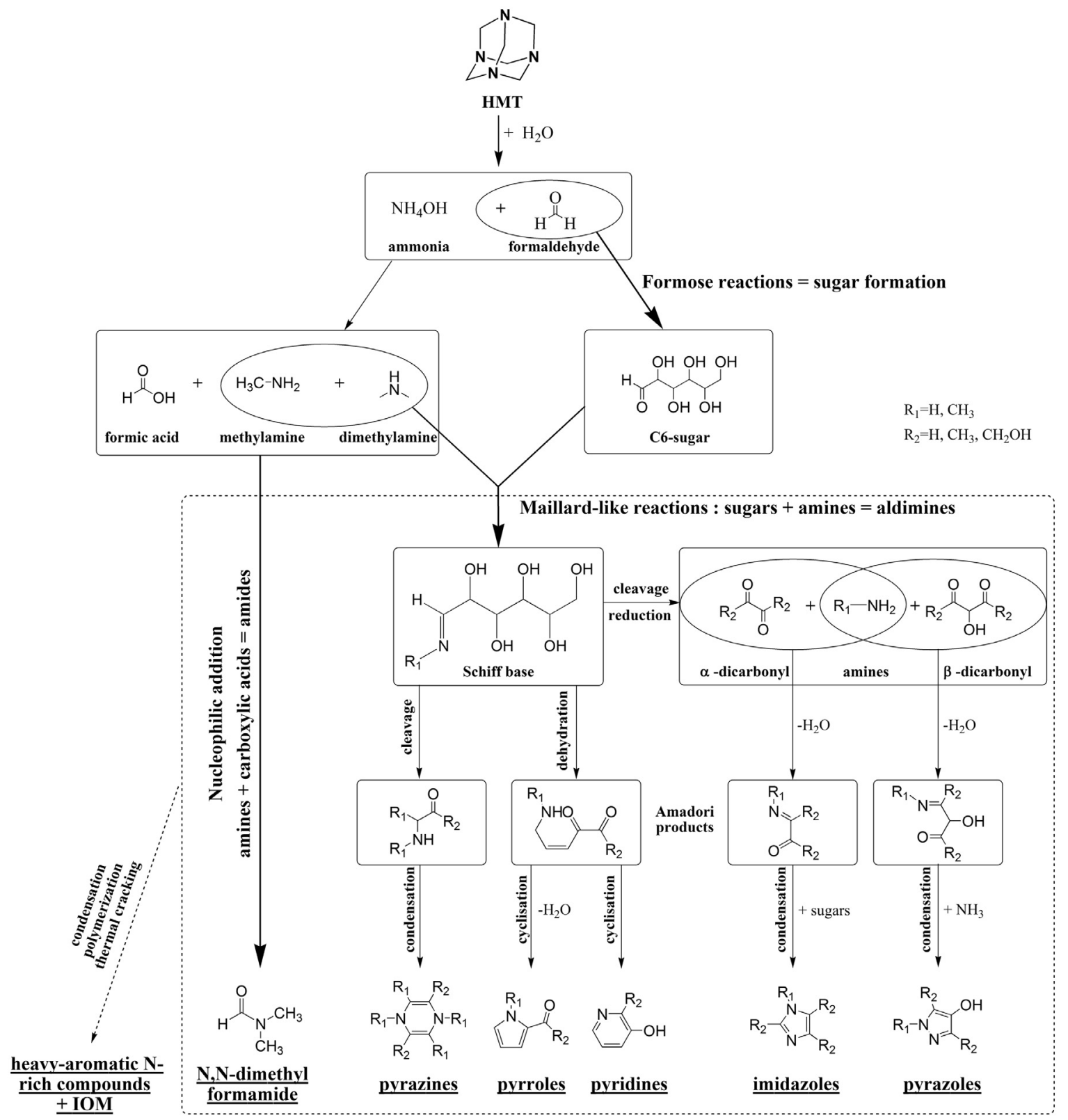

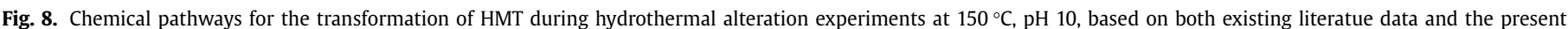

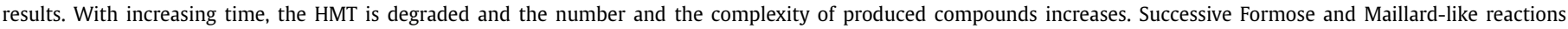
might have lead to the formation of the LC, HC and IOM products.

is twice as low as that of HMT, suggesting that nitrogen has been lost to the gas phase as $\mathrm{N}_{2}$ or $\mathrm{NH}_{3}$ during experiments.

Formaldehyde may condense and form sugar derivatives via the Formose reaction (Breslow, 1959; Butlerov, 1861). The Formose reaction generally refers to the formation of aldose and ketose sugars through the Aldol condensation of glycolaldehyde with formaldehyde (Breslow, 1959; Shapiro, 1987). Hydrothermal Formose reactions may lead to the formation of three to six carbon sugar molecules in a few minutes at $200{ }^{\circ} \mathrm{C}$ (Kopetzki and Antonietti, 2011) and to some $\mathrm{N}$-heterocycle compounds in the presence of ammonia (Kort, 1970).

At temperatures higher than $100^{\circ} \mathrm{C}$, an equimolar solution of formaldehyde and ammonia may also lead in a few hours to the formation of amine compounds, such as methylamine $\left(\mathrm{CH}_{3} \mathrm{NH}_{2}\right)$, dimethylamine $\left(\mathrm{CH}_{3}\right)_{2} \mathrm{NH}$ and trimethylamine $\left(\mathrm{CH}_{3}\right) 3 \mathrm{~N}$ (Jones and Wheatley, 1918; Werner, 1917). Noted that this reaction also leads to the formation of amino acids in acid hydrolysis conditions (Fox and Windsor, 1970; Hulett et al., 1971) and in alkaline hydrolysis conditions with the presence of glycolaldehyde (Kebukawa et al., 2017). In the present experiments, the formation of N-N-dimethyl formamide likely results from nucleophilic addition reactions between amine compounds and formic acid (Jursic and Zdravkovski, 1993; Mitchell and Reid, 1931), i.e. between products of formaldehyde oxidation (Fig. 8). Of note, the N-methyl formamide and the formamide compounds should also be formed, but cannot be detected without derivation by GC-MS.

With increasing experimental duration and with the temperature $\left(150^{\circ} \mathrm{C}\right)$, these amine compounds likely react with sugars through Amadori rearrangements and Maillard-like reactions (Ames, 1992; Nursten, 2005). In fact, although Maillard reactions generally involve amino acids and sugars (Maillard, 1912), the cyclic aldimines produced during the present experiments 
(pyridines, imidazoles and pyrazines with many alkyl substitutions) are common Maillard reaction products, as are soluble Orich compounds of high molecular weight, such as Shiff bases and di-carbonyl compounds (Ames, 1992; Nursten, 2005). Maillard-like reactions likely occur in the present experiments after the formose reaction because of the large quantity of available amines (Ellis, 1959; Namiki, 1988; Yamashita and Naraoka, 2014).

The continual increase of the molecular size index with increasing experimental duration highlights the production of high molecular weight soluble compounds (i.e. HC compounds). However, the chemical pathways that led to their formation remain unclear. These compounds could be seen as soluble melanoidins that constitute typical end products of Maillard-like reactions and, as such, may have formed via multiple condensation/polymerization reactions between low molecular weight intermediate products (Fig. 8).

After 20 days, the soluble compounds only slightly evolve with increasing experimental duration as indicated by GC-MS and XANES data, highlighting that a metastable thermodynamic equilibrium is likely achieved (Helgeson et al., 1998). Basic extrapolations suggest that such a mixture of soluble N-rich low and high molecular weight compounds may persist under asteroidal conditions for much longer durations.

\subsection{From soluble to insoluble organic matter}

A solid, N-rich IOM $\left(\mathrm{C}_{100} \mathrm{H}_{120} \mathrm{~N}_{30} \mathrm{O}_{31}\right)$ forms after 7 days of hydrothermal alteration (Figs. 5 and 6). This IOM can be seen as complex aromatic molecules containing N-rich (imines with many alkyl substitutions) and O-rich groups (ketones, phenols, carboxyls and hydroxyls) as shown by XANES and IR data. Its molecular structure does not vary with increasing experimental duration. Note that the $\mathrm{N} / \mathrm{C}$ of this IOM is similar to that of the soluble compounds $(\sim 0.28)$ and twice as low as the initial HMT value.

The formation of IOM from soluble compounds has been documented to occur during (secondary) thermal cracking of soluble asphaltenes at relatively low temperature $\left(\sim 150^{\circ} \mathrm{C}\right)$ in terrestrial settings (Bernard and Horsfield, 2014; Hill et al., 2003; Michels et al., 1996). These complex cracking reactions eventually lead to the formation of gases and of insoluble pyrobitumen residues that constitute are stable end products that may accumulate in a closed system (Behar et al., 1992; Bernard and Horsfield, 2014; Ungerer et al., 1988).

Complex organic materials, likely insoluble, may alternatively form through condensation, dehydration and cyclization reactions involving sugars produced from formaldehyde via the Formose reaction (Cody et al., 2011; Kebukawa et al., 2013; Kort, 1970; Weber, 2001). Such polymerization can occur in a few days at temperatures as low as $363 \mathrm{~K}$ if glycolaldehyde is added (with $\mathrm{Ca}(\mathrm{OH})_{2}$ as catalyst) (Kebukawa et al., 2013; Kopetzki and Antonietti, 2011). The presence of ammonia enhances the IOM yield significantly at temperatures below $150^{\circ} \mathrm{C}$ (Kebukawa et al., 2013; Kort, 1970). In such case, $\mathrm{N}$-rich heterocyclic compounds are formed and incorporated into the polymeric structure (Kebukawa et al., 2013; Kort, 1970). Kinetic studies have shown that the half-life for such organic solid formation at $0{ }^{\circ} \mathrm{C}$ is $\sim 2 \times 10^{4}$ years in the absence of ammonia vs only 70 years in the presence of ammonia (Kebukawa and Cody, 2015).

Alternatively, in the presence of amines, IOM may directly form through condensation/polymerization of Maillard-like products such as the soluble melanoidins discussed in the previous section. These reactions which require reactive molecules, such as unsaturated imine/carbonyl compounds (Benzing-Purdie et al., 1985), lead to the formation of polymeric, insoluble melanoidins with a high molecular weight (Namiki, 1988; Nursten, 2005). The final composition of such Maillard insoluble melanoidins depends on the amine/sugar ratio of the solution, as well as on temperature and $\mathrm{pH}$ (Cämmerer and Kroh, 1995).

The IOM that forms in the present experiments is insoluble in all organic solvents, as are chondritic IOM and terrestrial pyrobitumen, which might not be the case for the Kebukawa IOM and the Maillard insoluble melanoidins. Compared to these IOMs, the present IOM is significantly richer in nitrogen but contains less oxygen: it exhibits a $\mathrm{N} / \mathrm{C}$ of 0.28 and a $\mathrm{O} / \mathrm{C}$ of 0.32 (vs 0.1 and 0.4 for the Kebukawa IOM or up to 0.15 and up to 0.6 for the Maillard melanoides, respectively). The amount of IOM that forms is also very different (less than $1 \mathrm{wt} \%$ of the starting material vs. 15 or $30 \mathrm{wt} \%$ for the Kebukawa IOM or the Maillard insoluble melanoidins respectively). These differences are likely related to the large initial concentration of nitrogen in our solution (initial N/C of 0.57 vs 0.1 or less than 0.15 for the Kebukawa IOM or the Maillard insoluble melanoidins respectively) which has led to different chemical pathways.

Elucidating the exact pathway of IOM formation in the present experiments remains a difficult task, especially as several routes may occur simultaneously. The fact that the molecular structure of the IOM that forms in the present experiments does not significantly vary with increasing experimental duration highlights that its precursors are already formed before the end of the first week of hydrothermal alteration. Interestingly, the IOM and the HC form concomitantly (Fig. 7), which suggests that both the IOM and the $\mathrm{HC}$ are products of reactions involving LC or that the IOM results from reactions involving $\mathrm{LC}$ and the firstly formed $\mathrm{HC}$.

\subsection{Implications for the origin of chondritic $O M$}

A longstanding question in cosmochemistry is whether the chondritic organic compounds are formed in the ISM, in the protoplanetary disk or within asteroids during hydrothermal alteration (Aléon, 2010; Alexander et al., 2014, 2007; Glavin et al., 2010; Le Guillou et al., 2014; Remusat et al., 2010, 2009; Vinogradoff et al., 2017). A number of interstellar and nebular processes (ionmolecule reactions, gas-grain reactions, irradiation, heating) may lead to the formation of both soluble and insoluble OM (Danger et al., 2016, 2013; Herbst and van Dishoeck, 2009; Kuga et al., 2015; Laurent et al., 2015; Marcellus et al., 2017). Here, we investigated the impact of asteroidal hydrothermal conditions on a simple interstellar molecule such as HMT (which constitutes up to 50 wt\% of ice analog residues - Cottin et al., 2001; Muñoz Caro and Schutte, 2003; Vinogradoff et al., 2015, 2013, 2012) assuming that it had been accreted by asteroids (Caselli and Ceccarelli, 2012; Gudipati et al., 2015).

At $150{ }^{\circ} \mathrm{C}$ in hydrothermal conditions, HMT reacts (instantaneously on asteroidal timescales, i.e. $10^{6}$ years - Fujiya et al., 2012) to form a very diverse suite of $\mathrm{N}$-rich soluble compounds ( $>150$ species), as evidenced in the present study. The fact that CC contain amides and quite similar nitrogen-bearing aromatic molecules (Martins et al., 2008; Stoks and Schwartz, 1981; Yamashita and Naraoka, 2014) thus suggests that asteroids possibly accreted interstellar organic compounds such as HMT. Actually, more than thousands of different organic species have been identified in ice analog residues (Danger et al., 2016, 2013; Marcellus et al., 2015; Nuevo et al., 2008). Asteroidal hydrothermal alteration reactions involving interstellar organic compounds could be at the origin of a large part of the inventory of soluble chondritic molecules ( $>10,000$ different soluble molecules - Schmitt-Kopplin et al., 2010).

Although the chondritic IOM contains pyrrole and alkylpyridine groups (Pizzarello and Williams, 2012; Remusat et al., 2005b), it is not as N-rich as the IOM that forms in the present experiments $\left(\mathrm{C}_{100} \mathrm{H}_{60-80} \mathrm{O}_{16-18} \mathrm{~N}_{3} \mathrm{~S}_{2-7}\right.$ (Derenne and Robert, 2010) vs $\mathrm{C}_{100} \mathrm{H}_{120} \mathrm{O}_{31} \mathrm{~N}_{30}$ ). In fact, in terms of $\mathrm{N} / \mathrm{C}$ and XANES signatures, the insoluble organic products of the present experiments are closer to 
organic materials of ultracarbonaceous micrometeorites (UCAMM - N/C of 0.15-0.2 - Dartois et al., 2013; Yabuta et al., 2017). Yabuta et al. (2017) have recently interpreted the N-rich organic compounds from one UCAMM as products of incipient aqueous alteration reactions that likely occurred within water coming from locally melted cometary ice grains. These organic materials would thus be highly primitive and may contain the precursor of CC organic compounds (Yabuta et al., 2017). Altogether, the results of the present study thus shed a new experimental light on the cometasteroid continuum.

Importantly, the $\mathrm{N} / \mathrm{C}$ values of the soluble and insoluble products of the present experiments are lower than that of HMT, suggesting that significant amount of $\mathrm{NH}_{3}$ and/or $\mathrm{N}_{2}$ is released during hydrothermal alteration. Pizzarello and Williams (2012) detected up to $10 \mu \mathrm{g} \mathrm{mg}-1$ of $\mathrm{NH}_{3}$ that was likely IOM-bound, i.e. trapped within the IOM porosity, indicating that $\mathrm{NH}_{3}$ was present in the system during alteration. Still, a fraction of these gases could have been lost through degassing of the asteroids (Young et al., 2003; Alexander et al., 2010; Le Guillou et al., 2015), thereby having impacted the formation of the soluble and insoluble compounds (a loss of $\mathrm{NH}_{3}$ would have decreased the $\mathrm{pH}$ of the system while a loss of $\mathrm{H}_{2}$ would have increased its $\mathrm{fO}_{2}$ ). Asteroidal hydrothermal alteration of organic compounds likely occurred in a continuously changing environment.

Lastly, the insoluble/soluble ratio of the products of the present experiments is significantly lower than that of chondrites. According to Kebukawa et al. (2013) and Kebukawa and Cody (2015), the presence of ammonia significantly enhances the formation of IOM from formaldehyde via the formose reaction at $150{ }^{\circ} \mathrm{C}$. Given the large $\mathrm{N}$ concentration of the starting material of the present experiments ( $\mathrm{N} / \mathrm{C} \sim 0.57 \mathrm{vs} \sim 0.1$ for Kebukawa experiments) and the production of ammonia, the yield of IOM from HMT should thus have been quite high, at least if similar reaction pathways have occurred. The low IOM yield observed here ( $<1 \mathrm{wt} \% \mathrm{vs} \sim 15 \mathrm{wt} \%$ for Kebukawa experiments) suggests that, rather than the ammonia concentration, this is the addition of glycolaldehyde and $\mathrm{Ca}(\mathrm{OH})_{2}$ that enhances the Formose reaction and produces such high IOM yield in the Kebukawa experiments (Kebukawa et al., 2013; Kebukawa and Cody, 2015). This illustrates the need to properly identify the parameters that impact hydrothermal alteration reactions in addition to the temperature, the $\mathrm{pH}$, the nature of the starting materials and the reaction pathways, including any accreted organic or inorganic phase. In this respect, the exact role played by inorganic phases remains to be investigated. For instance, phyllosilicates, oxides and/or carbonates have been observed in close association with organic compounds in CC (Le Guillou et al., 2014; Le Guillou and Brearley, 2014; Zega et al., 2010). Because these minerals may exert an influence on the oxidation state of the system, their presence may strongly impact organic reactions (e.g., McCollom, 2013; Seewald, 2001).

\section{Concluding remarks}

The present study highlights the pertinence of performing laboratory experiments to improve the understanding of organic matter evolution in the context of asteroidal hydrothermal alteration, thereby shedding new light on the possible origin of chondritic organic compounds. The present experiments demonstrate that, if exposed to asteroidal conditions, a single molecule such as HMT will degrade and lead to the formation of hundreds of soluble compounds together with an insoluble organic material. These hydrothermal processes can be seen as instantaneous on asteroidal timescales. A step forward could be to investigate precisely the stability of organic hydrothermal products exposed to dry heating conditions, which likely existed in most asteroidal environments (Bonal et al., 2016; Remusat et al., 2016).

\section{Acknowledgment}

We gratefully acknowledge support from the program Emergences Ville de Paris (PI: L. Remusat), the program Emergence Sorbonne Universités (PI: S. Bernard) and the MNHN ATM program (PI: V. Vinogradoff). We are grateful to François Baudin (ISTep, Paris) for his help with elemental analysis, Matthieu Lebon and Xavier Gallet (HNHP, MNHN Paris) for their help with IR spectroscopy, and Christelle Anquetil and Sylvie Derenne (METIS, Paris) for their help with GC-MS. Special thanks go to Jian Wang and Yingshen Lu for their expert support of the STXM at the CLS and to Stefan Stanescu and Sufal Swaraj for their expert support of the STXM at SOLEIL. CLS is supported by the NSERC, the CIHR, the NRC, and the University of Saskatchewan. SOLEIL is supported by the CNRS, the CEA, the Region Ile de France, the Departmental Council of Essonne and the Region Centre. The research leading to the present results has been supported by the project CALIPSOplus under the Grant agreement 730872 from the EU Framework Programme for Research and Innovation HORIZON 2020. We thank two anonymous referees for helpful comments and Philip D. Nicholson for his editorial work.

\section{References}

Aléon, J., 2010. Multiple origins of nitrogen isotopic anomalies in meteorites and comets. Astrophys. J. 722, 1342. https://doi.org/10.1088/0004-637X/722/2/1342.

Alexander, C.M.O., Cody, G.D., De Gregorio, B.T., Nittler, L.R., Stroud, R.M., 2017. The nature, origin and modification of insoluble organic matter in chondrites, the major source of Earth's C and N. Chem. Erde - Geochem. 77, 227-256. https: //doi.org/10.1016/j.chemer.2017.01.007.

Alexander, C.M.O., Cody, G.D., Kebukawa, Y., Bowden, R., Fogel, M.L., Kilcoyne, A.L.D., Nittler, L.R., Herd, C.D.K., 2014. Elemental, isotopic, and structural changes in Tagish Lake insoluble organic matter produced by parent body processes. Meteorit. Planet. Sci. 49, 503-525. https://doi.org/10.1111/maps.12282.

Alexander, C.M.O., Fogel, M., Yabuta, H., Cody, G.D., 2007. The origin and evolution of chondrites recorded in the elemental and isotopic compositions of their macromolecular organic matter. Geochim. Cosmochim. Acta 71, 4380-4403. https: //doi.org/10.1016/j.gca.2007.06.052.

Alexander, C.M.O., Newsome, S.D., Fogel, M.L., Nittler, L.R., Busemann, H., Cody, G.D., 2010. Deuterium enrichments in chondritic macromolecular material-Implications for the origin and evolution of organics, water and asteroids. Geochim. Cosmochim. Acta 74, 4417-4437. https://doi.org/10.1016/j.gca. 2010.05.005.

Allamandola, L.J., Sandford, S.A., Valero, G.J., 1988. Photochemical and thermal evolution of interstellar/precometary ice analogs. Icarus 76, 225-252. https://doi. org/10.1016/0019-1035(88)90070-X

Alleon, J., Bernard, S., Guillou, C.L., Daval, D., Skouri-Panet, F., Kuga, M., Robert, F., 2017. Organic molecular heterogeneities can withstand diagenesis. Sci. Rep. 7, 1508. https://doi.org/10.1038/s41598-017-01612-8.

Alleon, J., Bernard, S., Guillou, C.L., Marin-Carbonne, J., Pont, S., Beyssac, O., McKeegan, K.D., Robert, F., 2016a. Molecular preservation of 1.88 Ga Gunflint organic microfossils as a function of temperature and mineralogy. Nat. Commun. 7. ncomms11977 https://doi.org/10.1038/ncomms11977.

Alleon, J., Bernard, S., Le Guillou, C., Daval, D., Skouri-Panet, F., Pont, S., Delbes, L. Robert, F., 2016b. Early entombment within silica minimizes the molecular degradation of microorganisms during advanced diagenesis. Chem. Geol. 437, 98-108. https://doi.org/10.1016/j.chemgeo.2016.05.034.

Alleon, J., Bernard, S., Remusat, L., Robert, F., 2015. Estimation of nitrogen-to-carbon ratios of organics and carbon materials at the submicrometer scale. Carbon 84, 290-298. https://doi.org/10.1016/j.carbon.2014.11.044

Ames, J.M., 1992. The maillard reaction. In: Hudson, B.J.F. (Ed.), Biochemistry of Food Proteins. Springer US, pp. 99-153. https://doi.org/10.1007/978-1-4684-9895-0_ 4

Anders, E., Hayatsu, R., Studier, M.H., 1973. Organic compounds in meteorites. Science 182, 781-790. https://doi.org/10.1126/science.182.4114.781.

Barré, P., Plante, A.F., Cécillon, L., Lutfalla, S., Baudin, F., Bernard, S., Christensen, B.T Eglin, T., Fernandez, J.M., Houot, S., Kätterer, T., Guillou, C.L., Macdonald, A. van Oort, F., Chenu, C., 2016. The energetic and chemical signatures of persistent soil organic matter. Biogeochemistry 130, 1-12. https://doi.org/10.1007/ s10533-016-0246-0.

Behar, F., Kressmann, S., Rudkiewicz, J.L., Vandenbroucke, M., 1992. Experimental simulation in a confined system and kinetic modelling of kerogen and oil cracking. Organ. Geochem. 19, 173-189. Proceedings of the 15th International Meeting on Organic Geochemistry https://doi.org/10.1016/0146-6380(92)90035-V.

Belkhou, R., Stanescu, S., Swaraj, S., Besson, A., Ledoux, M., Hajlaoui, M., Dalle, D. 2015. HERMES: a soft X-ray beamline dedicated to X-ray microscopy. J Synchrotron Radiat. 22, 968-979. https://doi.org/10.1107/S1600577515007778. 
Benzing-Purdie, L.M., Ripmeester, J.A., Ratcliffe, C.I., 1985. Effects of temperature on Maillard reaction products. J. Agric. Food Chem. 33, 31-33. https://doi.org/10. 1021/jf00061a009.

Bernard, S., Benzerara, K., Beyssac, O., Balan, E., Brown Jr, G.E., 2015. Evolution of the macromolecular structure of sporopollenin during thermal degradation. Heliyon 1, e00034. https://doi.org/10.1016/j.heliyon.2015.e00034.

Bernard, S., Horsfield, B., 2014. Thermal maturation of gas shale systems. Annu. Rev. Earth Planet. Sci. 42, 635-651. https://doi.org/10.1146 annurev-earth-060313-054850.

Bernard, S., Horsfield, B., Schulz, H.-M., Wirth, R., Schreiber, A., Sherwood, N., 2012 Geochemical evolution of organic-rich shales with increasing maturity: a STXM and TEM study of the Posidonia Shale (Lower Toarcian, northern Germany). Mar. Pet. Geol. Insights Shale Gas Explor. Exploit 31, 70-89. https://doi.org/10.1016/j. marpetgeo.2011.05.010.

Bernstein, M.P., Sandford, S.A., Allamandola, L.J., Chang, S., Scharberg, M.A., 1995. Organic compounds produced by photolysis of realistic interstellar and cometary ice analogs containing methanol. Astrophys. J. 454, 327. https://doi.org/10.1086/ 176485.

Blažzević, N., Kolbah, D., Belin, B., Šunjić, V., Kajfež, F., 1979. Hexamethylenetetramine: a versatile reagent in organic synthesis. Synthesis 3, 161-176. https: //doi.org/10.1055/s-1979-28602.

Bonal, L., Quirico, E., Flandinet, L., Montagnac, G., 2016. Thermal history of type 3 chondrites from the Antarctic meteorite collection determined by Raman spectroscopy of their polyaromatic carbonaceous matter. Geochim. Cosmochim. Acta 189, 312-337. https://doi.org/10.1016/j.gca.2016.06.017.

Boogert, A., Gerakines, P., Whittet, D., 2015. Observations of the icy universe. Annu. Rev. Astron. Astrophys. 53, 541-581. https://doi.org/10.1146 annurev-astro-082214-122348.

Boogert, A.C.A., Pontoppidan, K.M., Knez, C., Lahuis, F., Kessler-Silacci, J., Dishoeck, E.F., van Blake, G.A., Augereau, J.-C., Bisschop, S.E., Bottinelli, S., Brooke, T.Y., Brown, J., Crapsi, A., Evans II, N.J., Fraser, H.J., Geers, V., Huard, T.L., Jørgensen, J.K., Öberg, K.I., Allen, L.E., Harvey, P.M., Koerner, D.W., Mundy, L.G., Padgett, D.L., Sargent, A.I., Stapelfeldt, K.R., 2008. The c2d spitzer spectroscopic survey of ices around low-mass young stellar objects. $\mathrm{I}_{\text {. }} \mathrm{H}_{2} \mathrm{O}$ and the 5-8 $\mu \mathrm{m}$ bands. Astrophys. J. 678, 985. https://doi.org/10.1086/533425.

Bowey, J.E., Adamson, A.J., Whittet, D.C.B., 1998. The $10-\mu \mathrm{m}$ profile of molecularcloud and diffuse ISM silicate dust. Mon. Notices Royal Astron. Soc. 298, 131138. https://doi.org/10.1046/j.1365-8711.1998.01640.x.

Brearley, A.J., 2006. The action of water. In: Meteorites and the Early Solar System II. University of Arizona Press, pp. 584-624.

Breslow, R., 1959. On the mechanism of the formose reaction. Tetrahedron Lett. 1, 22-26. https://doi.org/10.1016/S0040-4039(01)99487-0.

Burton, A.S., Stern, J.C., Elsila, J.E., Glavin, D.P., Dworkin, J.P., 2012. Understanding prebiotic chemistry through the analysis of extraterrestrial amino acids and nucleobases in meteorites. Chem. Soc. Rev. 41, 5459-5472. https://doi.org/10.1039/ C2CS35109A.

Butlerov, A.M., 1861. Formation synthétique d'une substance sucrée. CR Acad. Sci $53,145-147$

Cämmerer, B., Kroh, L.W., 1995. Investigation of the influence of reaction conditions on the elementary composition of melanoidins. Food Chem. 53, 55-59. https: //doi.org/10.1016/0308-8146(95)95786-6.

Caselli, P., Ceccarelli, C., 2012. Our astrochemical heritage. Astron. Astrophys. Rev. 20, 56. https://doi.org/10.1007/s00159-012-0056-X.

Ciesla, F.J., Sandford, S.A., 2012. Organic synthesis via irradiation and warming of ice grains in the solar nebula. Science 336, 452-454. https://doi.org/10.1126/science. 1217291.

Coates, J., 2006. Interpretation of infrared spectra: a practical approach. Encyclopedia of Analytical Chemistry. John Wiley \& Sons, Ltd

Cody, G.D., Alexander, C.M.O.'D., 2005. NMR studies of chemical structural variation of insoluble organic matter from different carbonaceous chondrite groups. Geochim. Cosmochim. Acta 69, 1085-1097. https://doi.org/10.1016/j.gca.2004.08. 031.

Cody, G.D., Heying, E., Alexander, C.M.O., Nittler, L.R., Kilcoyne, A.L.D., Sandford, S.A. Stroud, R.M., 2011. Establishing a molecular relationship between chondritic and cometary organic solids. Proc. Natl Acad. Sci. 108, 19171-19176. https://doi.org/ 10.1073/pnas.1015913108.

Colthup, N.B., 1950. Spectra-structure correlations in the infra-red region. J. Opt. Soc. Am. 40, 397-400. https://doi.org/10.1364/JOSA.40.000397.

Cottin, H., Szopa, C., Moore, M.H., 2001. Production of hexamethylenetetramine in photolyzed and irradiated interstellar cometary ice analogs. Astrophys. J. 561, L139. https://doi.org/10.1086/324575.

Danger, G., Fresneau, A., Abou Mrad, N., de Marcellus, P., Orthous-Daunay, F.-R., Duvernay, F., Vuitton, V., Le Sergeant d'Hendecourt, L., Thissen, R., Chiavassa, T., 2016. Insight into the molecular composition of laboratory organic residues produced from interstellar/pre-cometary ice analogues using very high resolution mass spectrometry. Geochim. Cosmochim. Acta 189, 184-196. https://doi.org/10. 1016/j.gca.2016.06.014.

Danger, G., Orthous-Daunay, F.-R., de Marcellus, P., Modica, P., Vuitton, V., Duvernay, F., Flandinet, L., Le Sergeant d'Hendecourt, L., Thissen, R., Chiavassa, T., 2013. Characterization of laboratory analogs of interstellar/cometary organic residues using very high resolution mass spectrometry. Geochim. Cosmochim. Acta 118 184-201. https://doi.org/10.1016/j.gca.2013.05.015.

Dartois, E., Engrand, C., Brunetto, R., Duprat, J., Pino, T., Quirico, E., Remusat, L., Bardin, N., Briani, G., Mostefaoui, S., Morinaud, G., Crane, B., Szwec, N., Delauche, L., Jamme, F., Sandt, C., Dumas, P., 2013. UltraCarbonaceous Antarctic micrometeorites, probing the Solar System beyond the nitrogen snow-line. Icarus 224, 243-252. https://doi.org/10.1016/j.icarus.2013.03.002.
De Gregorio, B.T., Stroud, R.M., Nittler, L.R., Alexander, C.M.O., Kilcoyne, A.L.D., Zega, T.J., 2010. Isotopic anomalies in organic nanoglobules from Comet 81P/Wild 2: comparison to Murchison nanoglobules and isotopic anomalies induced in terrestrial organics by electron irradiation. Geochim. Cosmochim. Acta 74, 4454-4470. https://doi.org/10.1016/j.gca.2010.05.010

Derenne, S., Robert, F., 2010. Model of molecular structure of the insoluble organic matter isolated from Murchison meteorite. Meteorit. Planet. Sci. 45, 1461-1475. https://doi.org/10.1111/j.1945-5100.2010.01122.x.

Dhez, O., Ade, H., Urquhart, S.G., 2003. Calibrated NEXAFS spectra of some common polymers. J. Electron Spectrosc. Relat. Phenom. 128, 85-96. https://doi.org/10. 1016/S0368-2048(02)00237-2.

Ellis, G.P., 1959. The Maillard Reaction. Adv. Carbohydr. Chem. 14, 63-134. https: //doi.org/10.1016/S0096-5332(08)60223-4.

Fox, S.W., Windsor, C.R., 1970. Synthesis of amino acids by the heating of formaldehyde and ammonia. Science 170, 984-986. https://doi.org/10.1126/science.170. 3961.984.

Fujiya, W., Sugiura, N., Hotta, H., Ichimura, K., Sano, Y., 2012. Evidence for the late formation of hydrous asteroids from young meteoritic carbonates. Nat. Commun. 3, 627. https://doi.org/10.1038/ncomms1635

Gibb, E.L., Whittet, D.C.B., Boogert, A.C.A., Tielens, A.G.G.M., 2004. Interstellar ice: the Infrared Space Observatory Legacy. Astrophys. J. 151, 35. https://doi.org/10. 1086/381182

Glavin, D.P., Callahan, M.P., Dworkin, J.P., Elsila, J.E., 2010. The effects of parent body processes on amino acids in carbonaceous chondrites. Meteorit. Planet. Sci. 45, 1948-1972. https://doi.org/10.1111/j.1945-5100.2010.01132.x.

Gudipati, M.S., Abou Mrad, N., Blum, J., Charnley, S.B., Chiavassa, T., Cordiner, M.A., Mousis, O., Danger, G., Duvernay, F., Gundlach, B., Hartogh, P., Marboeuf, U., Simonia, I., Simonia, T., Theulé, P., Yang, R., 2015. Laboratory studies towards understanding comets. Space Sci. Rev. 197, 101-150. https://doi.org/10.1007/ s11214-015-0192-5.

Helgeson, H.C., Owens, C.E., Knox, A.M., Richard, L., 1998. Calculation of the standard molal thermodynamic properties of crystalline, liquid, and gas organic molecules at high temperatures and pressures. Geochim. Cosmochim. Acta 62, 985-1081. https://doi.org/10.1016/S0016-7037(97)00219-6.

Herbst, E., van Dishoeck, E.F., 2009. Complex organic interstellar molecules Annu. Rev. Astron. Astrophys. 47, 427-480. https://doi.org/10.1146/ annurev-astro-082708-101654.

Hill, R.J., Tang, Y., Kaplan, I.R., 2003. Insights into oil cracking based on laboratory experiments. Org. Geochem. 34, 1651-1672. https://doi.org/10.1016/ S0146-6380(03)00173-6

Hitchcock, A.P., Morin, C., Zhang, X., Araki, T., Dynes, J., Stöver, H., Brash, J., Lawrence, J.R., Leppard, G.G., 2005. Soft X-ray spectromicroscopy of biological and synthetic polymer systems. J. Electron Spectrosc. Relat. Phenom. 144-147, 259-269. Proceeding of the Fourteenth International Conference on Vacuum Ultraviolet Radiation Physics https://doi.org/10.1016/j.elspec.2005.01.279.

Hulett, H.R., Wolman, Y., Miller, S.L., Ibanez, J., Orò, J., Fox, S.W., Windsor, C.R., 1971. Formaldehyde and ammonia as precursors to prebiotic amino acids. Science 174, 1038-1041. https://doi.org/10.1126/science.174.4013.1038.

Jones, H.I., Wheatley, R., 1918. The preparation of methylamine. J. Am. Chem. Soc 40, 1411-1415. https://doi.org/10.1021/ja02242a007.

Jursic, B.S., Zdravkovski, Z., 1993. A simple preparation of amides from acids and amines by heating of their mixture. Synth. Commun. 23, 2761-2770. https:// doi.org/10.1080/00397919308013807.

Kaznatcheev, K.V., Karunakaran, C., Lanke, U.D., Urquhart, S.G., Obst, M., Hitchcock, A.P., 2007. Soft X-ray spectromicroscopy beamline at the CLS: commissioning results. Nuclear Instrum. Methods Phys. Res. Sect. A: Accel Spectrom. Detect. Assoc. Equip. 582, 96-99. Proceedings of the 14th National Conference on Synchrotron Radiation Research, SRI 2007 https://doi.org/10.1016/j.nima.2007. 08.083.

Kebukawa, Y., Cody, G.D., 2015. A kinetic study of the formation of organic solids from formaldehyde: implications for the origin of extraterrestrial organic solids in primitive Solar System objects. Icarus 248, 412-423. https://doi.org/10.1016/j. icarus.2014.11.005.

Kebukawa, Y., Kilcoyne, A.L.D., Cody, G.D., 2013. Exploring the potential formation of organic solids in chondrites and comets through polymerization of interstellar formaldehyde. Astrophys. J. 771, 19. https://doi.org/10.1088/0004-637X/771/ $1 / 19$.

Kebukawa, Y., Chan, Q.H.S., Tachibana, S., Kobayashi, K., Zolensky, M.E., 2017. Onepot synthesis of amino acid precursors with insoluble organic matter in planetesimals with aqueous activity. Sci. Adv. 3, e1602093. https://doi.org/10.1126/ sciadv.1602093.

Keil, K., 2000. Thermal alteration of asteroids: evidence from meteorites. Planet. Space Sci. 48, 887-903. Asteroids, Comets, Meteors (ACM) Conference https: //doi.org/10.1016/S0032-0633(00)00054-4.

Kopetzki, D., Antonietti, M., 2011. Hydrothermal formose reaction. New J. Chem. 35, 1787-1794. https://doi.org/10.1039/C1NJ20191C.

Kort, M.J., 1970. Reactions of free sugars with aqueous ammonia. Adv. Carbohydr. Chem. Biochem. 25, 311-349. https://doi.org/10.1016/S0065-2318(08)60431-X.

Kuga, M., Marty, B., Marrocchi, Y., Tissandier, L., 2015. Synthesis of refractory organic matter in the ionized gas phase of the solar nebula. Proc. Natl Acad. Sci. 112, 7129-7134. https://doi.org/10.1073/pnas.1502796112.

Laurent, B., Roskosz, M., Remusat, L., Robert, F., Leroux, H., Vezin, H., Depecker, C., Nuns, N., Lefebvre, J.-M., 2015. The deuterium/hydrogen distribution in chondritic organic matter attests to early ionizing irradiation. Nat. Commun. 6 . ncomms9567. https://doi.org/10.1038/ncomms9567. 
Le Guillou, C., Bernard, S., Brearley, A.J., Remusat, L., 2014. Evolution of organic matter in Orgueil, Murchison and Renazzo during parent body aqueous alteration: in situ investigations. Geochim. Cosmochim. Acta 131, 368-392. https: //doi.org/10.1016/j.gca.2013.11.020.

Le Guillou, C., Brearley, A., 2014. Relationships between organics, water and early stages of aqueous alteration in the pristine CR3.0 chondrite MET 00426 Geochim. Cosmochim. Acta 131, 344-367. https://doi.org/10.1016/j.gca.2013.10. 024

Le Guillou, C., Changela, H.G., Brearley, A.J., 2015. Widespread oxidized and hydrated amorphous silicates in CR chondrites matrices: Implications for alteration conditions and H2 degassing of asteroids. Earth Planet. Sci. Lett. 420, 162-173. https://doi.org/10.1016/j.epsl.2015.02.031.

Le Guillou, C., Remusat, L., Bernard, S., Brearley, A.J., Leroux, H., 2013. Amorphization and $\mathrm{D} / \mathrm{H}$ fractionation of kerogens during experimental electron irradiation: comparison with chondritic organic matter. Icarus 226, 101-110. https: //doi.org/10.1016/j.icarus.2013.05.003.

Leinweber, P., Kruse, J., Walley, F.L., Gillespie, A., Eckhardt, K.-U., Blyth, R.I.R. Regier, T., 2007. Nitrogen $K$-edge XANES - an overview of reference compounds used to identify 'unknown' organic nitrogen in environmental samples. J. Synchrotron Radiat. 14, 500-511. https://doi.org/10.1107/S0909049507042513.

Lessard, R., Cuny, J., Cooper, G., Hitchcock, A.P., 2007. Inner-shell excitation of gas phase carbonates and $\alpha, \gamma$-dicarbonyl compounds. Chem. Phys. 331, 289-303. https://doi.org/10.1016/j.chemphys.2006.10.020.

Llorca, J., Casanova, I, 2000. Reaction between $\mathrm{H}_{2}, \mathrm{CO}$, and $\mathrm{H}_{2} \mathrm{~S}$ over $\mathrm{Fe}$, Ni metal in the solar nebula: experimental evidence for the formation of sulfur-bearing organic molecules and sulfides. Meteorit. Planet. Sci. 35, 841-848. https://doi. org/10.1111/j.1945-5100.2000.tb01467.x.

Maillard, L.-C., 1912. Action des acides amines sur les sucres: formation des melanoidines par voie methodique. C.R. Hebd. Seances Acad. Sci. 154, 66-68

de Marcellus, P., Fresneau, A., Brunetto, R., Danger, G., Duvernay, F., Meinert, C., Meierhenrich, U.J., Borondics, F., Chiavassa, T., d'Hendecourt, L.L.S., 2017. Photo and thermochemical evolution of astrophysical ice analogues as a source for soluble and insoluble organic materials in Solar system minor bodies. Mon. Not. R. Astron. Soc. 464, 114-120. https://doi.org/10.1093/mnras/stw2292.

de Marcellus, P., Meinert, C., Myrgorodska, I., Nahon, L., Buhse, T., d'Hendecourt, L.L.S., Meierhenrich, U.J., 2015. Aldehydes and sugars from evolved precometary ice analogs: importance of ices in astrochemical and prebiotic evolution. Proc. Natl Acad. Sci. 112, 965-970. https://doi.org/10.1073/pnas.1418602112.

Martins, Z., Botta, O., Fogel, M.L., Sephton, M.A., Glavin, D.P., Watson, J.S., Dworkin, J.P., Schwartz, A.W., Ehrenfreund, P., 2008. Extraterrestrial nucleobases in the Murchison meteorite. Earth Planet. Sci. Lett. 270, 130-136. https://doi.org/ 10.1016/j.epsl.2008.03.026

Martins, Z., Sephton, M.A., 2009. Extraterrestrial amino acids. In: Hughes, A.B. (Ed.), Amino Acids, Peptides and Proteins in Organic Chemistry. Wiley-VCH Verlag GmbH \& Co. KGaA, pp. 1-42. https://doi.org/10.1002/9783527631766.ch1.

McCollom, T.M., 2013. The influence of minerals on decomposition of the n-alkyl$\alpha$-amino acid norvaline under hydrothermal conditions. Geochim. Cosmochim. Acta 104, 330-357. https://doi.org/10.1016/j.gca.2012.11.008

Mcsween, H.Y., 1979. Alteration in CM carbonaceous chondrites inferred from modal and chemical variations in matrix. Geochim. Cosmochim. Acta. https://doi.org/ 10.1016/0016-7037(79)90024-3.

Meissner, F., Schwiedessen, E., Othmer, D.F., 1954. Continuous production of hexamethylenetetramine. Ind. Eng. Chem. 46, 724-727. https://doi.org/10.1021/ ie50532a035.

Michels, R., Langlois, E., Ruau, O., Mansuy, L., Elie, M., Landais, P., 1996. Evolution of asphaltenes during artificial maturation: a record of the chemical processes. Energy Fuels 10, 39-48. https://doi.org/10.1021/ef9501410.

Mitchell, J.A., Reid, E.E., 1931. The preparation of aliphatic amides. J. Am. Chem. Soc. 53, 1879-1883. https://doi.org/10.1021/ja01356a037.

Morgan, W.A., Feigelson, E.D., Wang, H., Frenklach, M., 1991. A new mechanism for the formation of meteoritic kerogen-like material. Science 252, 109-112. https: //doi.org/10.1126/science.252.5002.109.

Muñoz Caro, G.M., Schutte, W.A., 2003. UV-photoprocessing of interstellar ice analogs: new infrared spectroscopic results. Astron. Astrophys. 412, 121-132. https://doi.org/10.1051/0004-6361:20031408.

Myneni, S.C.B., 2002. Soft X-ray spectroscopy and spectromicroscopy studies of organic molecules in the environment. Rev. Mineral. Geochem. 49, 485-579. https://doi.org/10.2138/gsrmg.49.1.485.

Namiki, M., 1988. Chemistry of maillard reactions: recent studies on the browning reaction mechanism and the development of antioxidants and mutagens. Adv. Food Res. 32, 115-184. https://doi.org/10.1016/S0065-2628(08)60287-6.

Nuevo, M., Auger, G., Blanot, D., d'Hendecourt, L., 2008. A detailed study of the amino acids produced from the vacuum uv irradiation of interstellar ice analogs. Orig. Life Evol. Biosph. 38, 37-56. https://doi.org/10.1007/s11084-007-9117-y.

Nursten, H., 2005. Maillard Reaction. Royal Society of Chemistry, Cambridge.

Nuth III, J.A., Johnson, N.M., Manning, S., 2008. A self-perpetuating catalyst for the production of complex organic molecules in protostellar nebulae. Astrophys. J. 673, L225. https://doi.org/10.1086/528741.

Orthous-Daunay, F.-R., Quirico, E., Beck, P., Brissaud, O., Dartois, E., Pino, T Schmitt, B., 2013. Mid-infrared study of the molecular structure variability of insoluble organic matter from primitive chondrites. Icarus 223, 534-543. https: //doi.org/10.1016/j.icarus.2013.01.003

Pizzarello, S., Williams, L.B., 2012. Ammonia in the early solar system: an account from carbonaceous meteorites. Astrophys. J. 749, 161. https://doi.org/10.1088/ 0004-637X/749/2/161
Remusat, L., 2016. Organics in primitive meteorites. EMU Notes Mineral. 15, 1-33. Remusat, L., Derenne, S., Robert, F., 2005a. New insight on aliphatic linkages in the macromolecular organic fraction of Orgueil and Murchison meteorite through ruthenium tetroxide oxidation. Geochim. Cosmochim. Acta 69, 43774386. https://doi.org/10.1016/j.gca.2005.05.003

Remusat, L., Derenne, S., Robert, F., Knicker, H., 2005b. New pyrolytic and spectroscopic data on Orgueil and Murchison insoluble organic matter: a different origin than soluble? Geochim. Cosmochim. Acta 69, 3919-3932. https://doi.org/10. 1016/j.gca.2005.02.032.

Remusat, L., Guan, Y., Wang, Y., Eiler, J.M., 2010. Accretion and preservation of D-rich organic particles in carbonaceous chondrites: evidence for important transport in the early solar system nebula. Astrophys. J. 713, 1048. https://doi.org/10.1088/ 0004-637X/713/2/1048

Remusat, L., Palhol, F., Robert, F., Derenne, S., France-Lanord, C., 2006. Enrichment of deuterium in insoluble organic matter from primitive meteorites: a solar system origin? Earth Planet. Sci. Lett. 243, 15-25. https://doi.org/10.1016/j.epsl.2005.12. 010.

Remusat, L., Piani, L., Bernard, S., 2016. Thermal recalcitrance of the organic D-rich component of ordinary chondrites. Earth Planet. Sci. Lett. 435, 36-44. https:/ doi.org/10.1016/j.epsl.2015.12.009.

Remusat, L., Robert, F., Meibom, A., Mostefaoui, S., Delpoux, O., Binet, L., Gourier, D. Derenne, S., 2009. Proto-planetary disk chemistry recorded by D-rich organic radicals in carbonaceous chondrites. Astrophys. J. 698, 2087. https://doi.org/10 1088/0004-637X/698/2/2087.

Robin, N., Bernard, S., Miot, J., Blanc-Valleron, M.-M., Charbonnier, S., Petit, G., 2015 Calcification and diagenesis of bacterial colonies. Minerals 5, 488-506. https: /doi.org/10.3390/min5030488.

Rouchon, V., Bernard, S., 2015. Mapping iron gall ink penetration within paper fibres using scanning transmission X-ray microscopy. J. Anal. At. Spectrom. 30, 635641. https://doi.org/10.1039/C4JA00358F.

Sagan, C., Khare, B.N., 1979. Tholins: organic chemistry of interstellar grains and gas. Nature 277, 102-107. https://doi.org/10.1038/277102a0.

Saito, M., Kimura, Y., 2009. Origin of organic globules in meteorites: laboratory simulation using aromatic hydrocarbons. Astrophys. J. 703, L147. https://doi.org/10. 1088/0004-637X/703/2/L147.

Schmitt-Kopplin, P., Gabelica, Z., Gougeon, R.D., Fekete, A., Kanawati, B., Harir, M. Gebefuegi, I., Eckel, G., Hertkorn, N., 2010. High molecular diversity of extraterrestrial organic matter in Murchison meteorite revealed 40 years after its fall. Proc. Natl Acad. Sci. 107, 2763-2768. https://doi.org/10.1073/pnas.0912157107.

Scott, E.R.D., Krot, A.N., 2007. 1.07 - Chondrites and their components. In: Holland, H.D., Turekian, K.K. (Eds.), Treatise on Geochemistry. Pergamon, Oxford, pp. 1-72. https://doi.org/10.1016/B0-08-043751-6/01145-2.

Seewald, J.S., 2001. Aqueous geochemistry of low molecular weight hydrocarbons at elevated temperatures and pressures: constraints from mineral buffered laboratory experiments. Geochim. Cosmochim. Acta 65, 1641-1664. https://doi.org/10. 1016/S0016-7037(01)00544-0.

Shapiro, R., 1987. Prebiotic ribose synthesis: a critical analysis. Orig. Life Evol Biosph. 18, 71-85. https://doi.org/10.1007/BF01808782.

Solomon, D., Lehmann, J., Kinyangi, J., Liang, B., Heymann, K., Dathe, L., Hanley, K., Wirick, S., Jacobsen, C., 2009. Carbon (1s) NEXAFS spectroscopy of biogeochemically relevant reference organic compounds. Soil Sci. Soc. Am. J. 73, 1817-1830. https://doi.org/10.2136/sssaj2008.0228.

Stoks, P.G., Schwartz, A.W., 1981. Nitrogen-heterocyclic compounds in meteorites: significance and mechanisms of formation. Geochim. Cosmochim. Acta 45, 563569. https://doi.org/10.1016/0016-7037(81)90189-7.

Swaraj, S., Belkhou, R., Stanescu, S., Rioult, M., Besson, A., Hitchcock, A.P., 2017. Performance of the HERMES beamline at the carbon K-edge. J. Phys.: Conf. Ser. 849 012046. https://doi.org/10.1088/1742-6596/849/1/012046.

Theulé, P., Duvernay, F., Danger, G., Borget, F., Bossa, J.B., Vinogradoff, V., Mispelaer, F., Chiavassa, T., 2013. Thermal reactions in interstellar ice: A step towards molecular complexity in the interstellar medium. Adv. Space Res. 52 1567-1579. https://doi.org/10.1016/j.asr.2013.06.034.

Ungerer, P., Behar, F., Villalba, M., Heum, O.R., Audibert, A., 1988. Kinetic modelling of oil cracking. Org. Geochem. 13, 857-868. Proceedings of the 13th International Meeting on Organic Geochemistry https://doi.org/10.1016/0146-6380(88) 90238-0

Urquhart, S.G., Hitchcock, A.P., Smith, A.P., Ade, H.W., Lidy, W., Rightor, E.G., Mitchell, G.E., 1999. NEXAFS spectromicroscopy of polymers: overview and quantitative analysis of polyurethane polymers. J. Electron Spectrosc. Relat. Phenom. 100, 119-135. https://doi.org/10.1016/S0368-2048(99)00043-2.

Vinogradoff, V., Duvernay, F., Danger, G., Theulé, P., Chiavassa, T., 2011. New insight into the formation of hexamethylenetetramine (HMT) in interstellar and cometary ice analogs. Astron. Astrophys. 530, A128. https://doi.org/10.1051/ 0004-6361/201116688.

Vinogradoff, V., Duvernay, F., Fray, N., Bouilloud, M., Chiavassa, T., Cottin, H. 2015. Carbon dioxide influence on the thermal formation of complex organic 2015. Calt 809, L18, https://doi.org/ $10.1088 / 2041-8205 / 809 / 2 /$ L18

Vinogradoff, V., Fray, N., Duvernay, F., Briani, G., Danger, G., Cottin, H., Theulé, P., Chiavassa, T., 2013. Importance of thermal reactivity for hexamethylenetetramine formation from simulated interstellar ices. Astron. Astrophys. 551, A128. https: //doi.org/10.1051/0004-6361/201220870.

Vinogradoff, V., Le Guillou, C., Bernard, S., Binet, L., Cartigny, P., Brearley, A.J., Remusat, L., 2017. Paris vs. Murchison: impact of hydrothermal alteration on organic matter in CM chondrites. Geochim. Cosmochim. Acta. https://doi.org/10 1016/j.gca.2017.06.009. 
Vinogradoff, V., Rimola, A., Duvernay, F., Danger, G., Theulé, P., Chiavassa, T., 2012. The mechanism of hexamethylenetetramine (HMT) formation in the solid state at low temperature. Phys. Chem. Chem. Phys. 14, 12309-12320. https://doi.org/ 10.1039/C2CP41963G.

Wang, J., Morin, C., Li, L., Hitchcock, A.P., Scholl, A., Doran, A., 2009. Radiation damage in soft X-ray microscopy. J. Electron Spectrosc. Relat. Phenom. Radiat. Damage 170, 25-36. https://doi.org/10.1016/j.elspec.2008.01.002.

Weber, A.L., 2001. The sugar model: catalysis by amines and amino acid products. Orig. Life Evol. Biosph. 31, 71-86. https://doi.org/10.1023/A:1006750423942.

Werner, A.E., 1917. LXXII.Methylation by means of formaldehyde. Part I. The mechanism of the interaction of formaldehyde and ammonium chloride; the preparation of methylamine and of dimethylamine. https://doi.org/10.1039/ CT9171100844.

Yabuta, H., Noguchi, T., Itoh, S., Nakamura, T., Miyake, A., Tsujimoto, S., Ohashi, N. Sakamoto, N., Hashiguchi, M., Abe, K., Okubo, A., David Kilcoyne, A.L., Tachibana, S., Okazaki, R., Terada, K., Ebihara, M., Nagahara, H., 2017. Formation of an ultracarbonaceous antarctic micrometeorite through minimal aqueous alteration in a small porous icy body. Geochim. Cosmochim. Acta. https: //doi.org/10.1016/j.gca.2017.06.047.
Yabuta, H., Williams, L.B., Cody, G.D., Alexander, C.M.O., Pizzarello, S., 2007. The insoluble carbonaceous material of CM chondrites: a possible source of discrete organic compounds under hydrothermal conditions. Meteorit. Planet. Sci. 42. 37-48. https://doi.org/10.1111/j.1945-5100.2007.tb00216.x.

Yamashita, Y., Naraoka, H., 2014. Two homologous series of alkylpyridines in the Murchison meteorite. Geochem. J. 48, 519-525. https://doi.org/10.2343/ geochemj.2.0340.

Young, E.D., Zhang, K.K., Schubert, G., 2003. Conditions for pore water convection within carbonaceous chondrite parent bodies - implications for planetesimal size and heat production. Earth Planet. Sci. Lett. 213, 249-259. https: //doi.org/10.1016/S0012-821X(03)00345-5.

Zega, T.J., Alexander, C.M.O., Busemann, H., Nittler, L.R., Hoppe, P., Stroud, R.M., Young, A.F., 2010. Mineral associations and character of isotopically anomalous organic material in the Tagish Lake carbonaceous chondrite. Geochim. Cosmochim. Acta 74, 5966-5983. https://doi.org/10.1016/j.gca.2010.07.018. 